\title{
HIV gp120- and methamphetamine-mediated oxidative stress induces astrocyte apoptosis via cytochrome P450 2E1
}

\author{
A Shah ${ }^{1}$, S Kumar ${ }^{1}$, SD Simon ${ }^{2}$, DP Singh ${ }^{3}$ and A Kumar ${ }^{\star, 1}$
}

HIV-1 glycoprotein 120 (gp120) is known to cause neurotoxicity via several mechanisms including production of proinflammatory cytokines/chemokines and oxidative stress. Likewise, drug abuse is thought to have a direct impact on the pathology of HIV-associated neuroinflammation through the induction of proinflammatory cytokines/chemokines and oxidative stress. In the present study, we demonstrate that gp120 and methamphetamine (MA) causes apoptotic cell death by inducing oxidative stress through the cytochrome P450 (CYP) and NADPH oxidase (NOX) pathways. The results showed that both MA and gp120 induced reactive oxygen species (ROS) production in concentration- and time-dependent manners. The combination of gp120 and MA also induced CYP2E1 expression at both mRNA (1.7 \pm 0.2 - and $2.8 \pm 0.3$-fold in SVGA and primary astrocytes, respectively) and protein (1.3 \pm 0.1 -fold in SVGA and $1.4 \pm 0.03$-fold in primary astrocytes) levels, suggesting the involvement of CYP2E1 in ROS production. This was further confirmed by using a selective inhibitor of CYP2E1, diallylsulfide (DAS), and CYP2E1 knockdown using siRNA, which significantly reduced ROS production $(30-60 \%)$. As the CYP pathway is known to be coupled with the NOX pathway, including Fenton-Weiss-Haber (FWH) reaction, we examined whether the NOX pathway is also involved in ROS production induced by either gp120 or MA. Our results showed that selective inhibitors of NOX, diphenyleneiodonium (DPI), and FWH reaction, deferoxamine (DFO), also significantly reduced ROS production. These findings were further confirmed using specific siRNAs against NOX2 and NOX4 (NADPH oxidase family). We then showed that gp120 and MA both induced apoptosis (caspase-3 activity and DNA lesion using TUNEL (terminal deoxynucleotidyltransferase-mediated dUTP nick-end labeling) assay) and cell death. Furthermore, we showed that DAS, DPI, and DFO completely abolished apoptosis and cell death, suggesting the involvement of CYP and NOX pathways in ROS-mediated apoptotic cell death. In conclusion, this is the first report on the involvement of CYP and NOX pathways in gp120/MA-induced oxidative stress and apoptotic cell death in astrocytes, which has clinical implications in neurodegenerative diseases, including neuroAIDS.

Cell Death and Disease (2013) 4, e850; doi:10.1038/cddis.2013.374; published online 10 October 2013

Subject Category: Neuroscience

The HIV-1 envelope protein, glycoprotein 120 (gp120), mediates entry of the virus into host cells, including $T$ cells and monocytes. Infected monocytes can traffic across the blood-brain barrier (BBB) into the central nervous system (CNS) where the virus can replicate in microglia and astrocytes. $^{1,2}$ The neurotoxic effects of HIV-1 proteins, including gp120, can be either through direct or indirect mechanisms. ${ }^{3}$ In terms of indirect mechanisms, HIV-1 gp120 has been shown to induce the expression of proinflammatory chemokines and cytokines, ${ }^{4-6}$ and to induce oxidative stress in astrocytes and microglia. ${ }^{7,8}$ Both in vitro and in vivo models have been used to demonstrate that gp120 can directly induce apoptosis in neurons. ${ }^{9}$
A variety of illicit substances such as morphine, cocaine, and methamphetamine (MA) have been shown to exacerbate HIV-associated neurotoxicity. ${ }^{9-11}$ In the CNS, MA has been shown to increase excitotoxicity, ${ }^{12}$ BBB damage, ${ }^{12,13}$ the expression of proinflammatory cytokines, ${ }^{14}$ and oxidative stress. ${ }^{13,15}$ Owing to its structural similarity to dopamine, MA has been shown to increase dopaminergic activity leading to increased intracellular oxidative stress and neurotoxicity. ${ }^{16}$ These findings are consistent with the protective effect of various antioxidants against MA-induced neurotoxicity. ${ }^{17-19}$ Thus, oxidative stress is suggested to have an important role in MA-mediated neurotoxicity. Furthermore, it is likely that concurrent HIV infection and substance abuse may cause

\footnotetext{
${ }^{1}$ Division of Pharmacology and Toxicology, School of Pharmacy, University of Missouri-Kansas City, Kansas City, MO, USA; ${ }^{2}$ Department of Informatic Medicine and Personalized Health, School of Medicine, University of Missouri-Kansas City, Kansas City, MO, USA and ${ }^{3}$ Department of Ophthalmology and Visual Sciences, University of Nebraska Medical Center, Omaha, NE, USA

${ }^{*}$ Corresponding author: A Kumar, Division of Pharmacology and Toxicology, School of Pharmacy, University of Missouri-Kansas City, 2464 Charlotte Street, Kansas City, MO 64108, USA. Tel: +1 816235 1792; Fax: +1 816235 1776; E-mail:kumaran@umkc.edu

Keywords: methamphetamine; gp120; cytochrome P450; astrocytes; oxidative stress

Abbreviations: BBB, blood-brain barrier; CNS, central nervous system; CYP, cytochrome P450; DAS, diallylsulfide; DFO, deferoxamine; DPI, diphenyleneiodonium; FWH, Fenton-Weiss-Haber reaction; gp120, glycoprotein 120; GAPDH, glyceraldehyde 3-phosphate dehydrogenase; $\mathrm{H}_{2} \mathrm{DC}-\mathrm{FDA}, 5$-(and-6)-chloromethyl-2',7'dichlorodihydrofluorescein diacetate; HFA, human fetal astrocytes; MA, methamphetamine; MTT, 3-(4,5-dimethylthioazol-2-yl)-2,5-diphenyl tetrazolium bromide; NAC, N-acetyl cysteine; NOX, NADPH oxidase; OP, orphenadrine; ROS, reactive oxygen species; TUNEL, terminal deoxynucleotidyltransferase-mediated dUTP nickend labeling; vit. C, vitamin C; vit. E, vitamin $\mathrm{E}$

Received 20.3.13; revised 05.8.13; accepted 20.8.13; Edited by GM Fimia
} 
enhanced neurotoxicity. We have recently shown that gp120 and MA cooperate synergistically to induce the proinflammatory cytokine IL- 6 in astrocytes. ${ }^{14}$ However, it is not known whether such cooperation exists at the oxidative stress level.

Recent advances suggest the involvement of various cytochrome P450 (CYP) enzymes in neurotoxicity, perhaps as a result of production of reactive oxygen species (ROS) and/or reactive metabolites. The involvement of CYP46 in Alzheimer's disease ${ }^{20}$ and CYP2D6 in Parkinson's disease ${ }^{21}$ illustrates the contributions of these enzymes to neurodegenerative disorders. Although the role of CYPs in drug abuse and HIV-1 neuropathogenesis is unexplored, a recent study suggests a potential role for CYP2E1 in alcoholmediated neurotoxicity. ${ }^{22}$ Furthermore, NADPH oxidase (NOX) has been shown to induce ROS both independently and in association with CYP-mediated drug metabolism. Therefore, we hypothesize that CYP and NOX pathways are involved in HIV- and/or MA-induced neurotoxicity.

The present study was undertaken to determine whether viral protein gp120 and MA cooperates to cause enhanced oxidative stress leading to increased cell death and whether CYP is involved in gp120/MA-mediated oxidative stress and astrocyte apoptosis.

\section{Results}

HIV-1 gp120 and MA independently increase oxidative stress in astrocytes. Several studies have reported gp120mediated induction of oxidative stress in astrocytes. ${ }^{7,8,23}$ In this study, we used SVGA astrocytic cells and transfected them with a plasmid containing a gp120 expression vector. Astrocytes were transfected for different lengths of time and ROS was measured using 5-(and-6)-chloromethyl$2^{\prime}, 7^{\prime}$-dichlorodihydrofluorescein diacetate $\left(\mathrm{H}_{2} \mathrm{DC}-\mathrm{FDA}\right)$ on flow cytometer. As shown in Figure 1a, gp120 induced ROS production with a peak increase $(75.2 \pm 10.6 \%)$ at $24 \mathrm{~h}$ compared with mock-transfected cells. To confirm the effect of exogenous gp120, we used recombinant gp120IIIB protein and obtained similar results that showed an increase in ROS production as early as $6 \mathrm{~h}$. The peak ROS production $(21.7 \pm 5.1 \%)$ was observed at $12 \mathrm{~h}$ of exposure (Figure 1b). The increase in ROS production was also found to be concentration-dependent as $2 \mathrm{nM}$ gp120IIIB showed $22.1 \pm 3.2 \%$ increase compared with the control (Figure 1c).

MA is known to induce oxidative stress in various cell types in the brain mainly via dopaminergic mechanism. ${ }^{24,25}$ To determine the effect of MA on ROS production, we treated the astrocytes with varying concentrations of MA. The results showed a concentration-dependent increase in ROS, with $500 \mu \mathrm{M}$ showing maximal ROS $(37.3 \pm 2.4 \%)$ at $24 \mathrm{~h}$ (Figure 1d). Furthermore, to test the effect of single dose of MA on ROS production, astrocytes were treated with $500 \mu \mathrm{M}$ MA for various lengths of time. This dose of MA was based on the blood concentrations and tissue/serum compartmentalization as reported in literatures. ${ }^{26-28}$ Furthermore, the binge administration of MA in the range of $250 \mathrm{mg}-1 \mathrm{~g}$ has been found to produce brain concentrations of MA between 164 and $776 \mu \mathrm{M} .{ }^{27}$ As expected, MA increased ROS production in a time-dependent manner and peak ROS production $(29.4 \pm 3.0 \%)$ was observed at $24 \mathrm{~h}$ (Figure 1e).

HIV-1 gp120 and MA additively increase oxidative stress in astrocytes. Upon demonstrating that both MA and gp120 independently induced ROS in SVGA astrocytes; we examined whether MA and gp120 interact additively or synergistically to increase oxidative stress. We treated SVGA astrocytes with $500 \mu \mathrm{M}$ MA and transfected with $2 \mu \mathrm{g}$ of gp120-plasmid followed by measurement of ROS at $24 \mathrm{~h}$ after treatment. Clearly, astrocytes treated with both MA and gp120 showed ROS levels $(107.1 \pm 12.9 \%)$ higher than either MA $(41.8 \pm 4.4 \%)$ or gp120 alone $(67.7 \pm 11.0 \%)$ (Figure 2a). Furthermore, two-factor ANOVA model suggested an additive effect rather than synergistic $(P=0.91)$. To confirm the finding in primary astrocyte culture, we used $2 \mathrm{nM}$ recombinant gp120IIIB protein in combination with $500 \mu \mathrm{M}$ MA. We observed similar results in terms of ROS production in primary human fetal astrocytes using flow cytometry $(5.9 \pm 2.5 \%$ for MA, $24.3 \pm 4.0 \%$ for gp 120 , and $54.8 \pm 13.1 \%$ for $M A+$ gp120) (Figure $2 b$ ). Similarly, the fluorescence observed using microscopy was significantly higher when cells were treated with both gp120 and MA as compared with cells treated with either agent alone in SVGA astrocytes (Figure 2c) and primary astrocytes (Figure 2d).

As oxidative stress is known to be associated with both cell death $^{29}$ and cell proliferation, ${ }^{30}$ depending on the extent of the ROS production, we analyzed the functional consequences of MA and gp120 treatments in SVGA astrocytes. Clearly, the treatment with MA and gp120 significantly increased the level of terminal deoxynucleotidyltransferase-mediated dUTP nickend labeling (TUNEL)-positive astrocytes when compared with MA or gp120 alone (Figure 2e). In parallel experiments, we quantified the level of cell death induced by MA and/or gp120 using 3-(4,5-dimethylthiazol-2-yl)-2,5-diphenyltetrazolium bromide (MTT) assay and found that cells treated with gp120 and MA showed an additive effect and significantly higher $(P \leq 0.01)$ cell death was observed $(14.1 \pm 2.9 \%)$ when compared with either MA $(6.8 \pm 1.5 \%)$ or gp120 $(8.3 \pm 1.8 \%)$ alone (Figure 2f). These observations indicated that the oxidative stress induced by gp120 and/or MA was lethal to astrocytes and MA and gp120 additively increase the cellular toxicity.

As the combination of MA and gp120 showed increased oxidative stress, we sought to address the molecular mechanism responsible for these effects. First, we pretreated SVGA cells with $100 \mu \mathrm{M}$ vitamin C (vit. C), a common antioxidant, followed by treatments with gp120 and MA. As expected, vit. $\mathrm{C}$ alone reduced basal levels of ROS production. However, it also abolished the ROS generated by either MA or gp120 alone, as well as MA + gp120 (Figure 3a). In addition, vit. $C$ also abrogated cell death caused by MA and gp120 alone and also in combination (Figure 3b). Similarly, we also used vit. E, another canonical ROS quencher to confirm our results with vit. C. Surprisingly, TROLOX, a water-soluble form of vit. E, did not reduce ROS production (Supplementary Figure 1A). However, when we used vit. $E$ in its native form ( $\alpha$-tocopherol), it reduced ROS generated by MA or gp120 alone, as well as MA + gp120 (Figure 3c). It also rescued the astrocytes from cell death (Figure $3 \mathrm{~d}$ ). Although $\mathrm{N}$-acetyl 
a

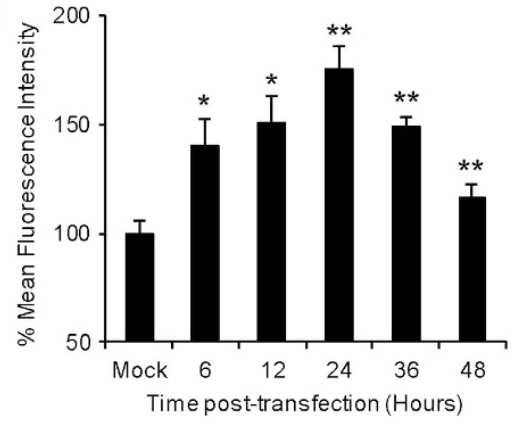

C

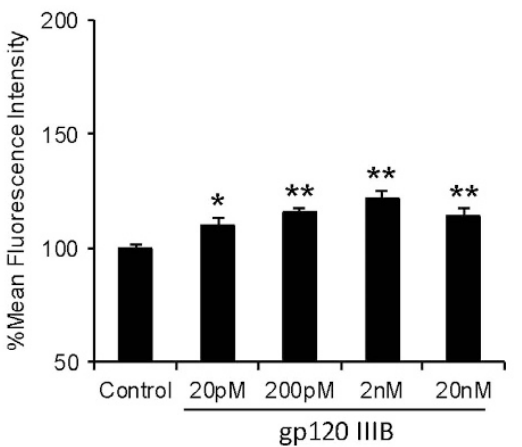

b

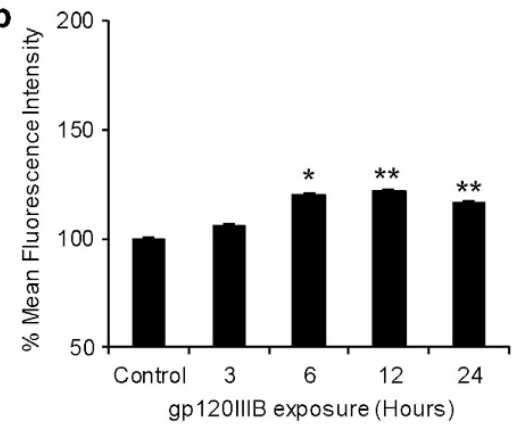

d

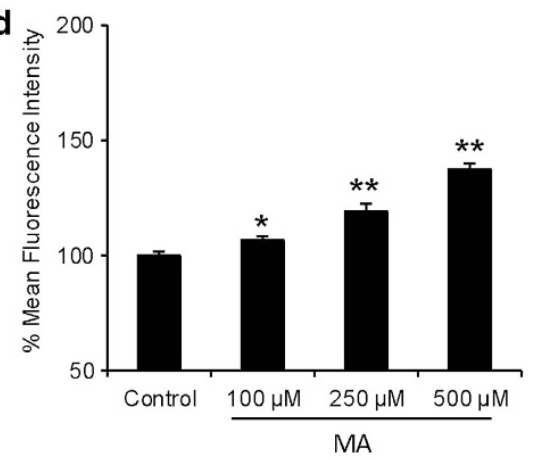

e

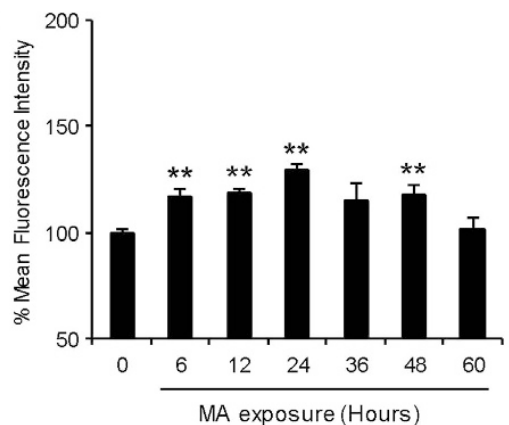

Figure 1 HIV-1 gp120 and MA increase oxidative stress in time-dependent manner. SVGA astrocytes were seeded at $2.75 \times 10^{5}$ per well in 12 -well plates and treated with appropriate agents. The cells were then washed two times with PBS and incubated with $5 \mu \mathrm{M}$ solution of $\mathrm{H}_{2} \mathrm{DC}$-FDA for 30 min at $37^{\circ} \mathrm{C}$. This was followed by two washes with PBS and fluorescence intensity was measured using flow cytometer. (a) Cells were transfected with $2 \mu \mathrm{g}$ of plasmid expressing gp 120 for $5 \mathrm{~h}$ using Lipofectamine 2000 followed by replacement of the transfection mix with complete medium. ROS was measured after $6,12,24,36$, and $48 \mathrm{~h}$ after transfection. (b) Cells were treated with $200 \mu \mathrm{M}$ of recombinant gp120 IIIB and ROS was measured after 3, 6, 12, and $24 \mathrm{~h}$ after the treatment. (c) Cells were treated at varying concentrations of gp120IIIB and ROS was measured after $24 \mathrm{~h}$ of exposure. (d) Cells were treated with different concentrations of MA and ROS was measured after $24 \mathrm{~h}$ of exposure. (e) Cells were treated with $500 \mu \mathrm{M}$ MA and ROS was measured. The bars represent mean \pm S.E. of at least two independent experiments with each treatment in triplicates. The $P$-value $\leq 0.05\left(^{*}\right)$ and $\leq 0.01$ $\left.{ }^{* *}\right)$ were considered statistically significant using two-tailed Student's $t$-test

cysteine (NAC) has been shown to abrogate gp120-mediated ROS production in astrocytes, ${ }^{23}$ in our studies NAC did not show any reduction in ROS production (Supplementary Figure 1B). This observation is similar to our previous report, where we showed that NAC did not reduce alcohol-mediated ROS in astrocytes. ${ }^{22}$

MA and gp120 induced the expression of CYP. As CYP has been shown to be involved in oxidative stress in many organs/tissues including the brain, we measured the mRNA expression levels of various CYPs in astrocytes treated with MA and/or gp120. Both MA and gp120 induced different isozymes of CYP at variable levels (Figure 4a). Among the isozymes induced, CYP2E1 (1.7 \pm 0.2 -fold), CYP2D6 (2.3 \pm 0.3 -fold), and CYP2B6 (3.2 \pm 03 -fold) clearly showed additive increases (two-way ANOVA showed $P$-value $=0.34$, 0.18 , and 0.84 , respectively, suggesting the absence of synergy) in the levels of mRNA expression with gp120+MA when compared with either MA (nonsignificant change for CYP2E1 and CYP2D6 and 2.8 \pm 0.3 -fold for CYP2B6) or gp120 (1.3 \pm 0.1 -fold for CYP2E1 and 1.8 \pm 0.3 -fold for CYP2D6 and nonsignificant for CYP2B6) alone (Figure 4a). These results were further confirmed at the protein level for CYP2E1 (1.3 \pm 0.1-fold for gp120 + MA), CYP2D6 (1.7 \pm 0.2-fold for gp120+MA), and CYP2B6 (1.4 \pm 0.1 -fold for gp120 + MA) (Figure 4b). Furthermore, to confirm this phenomenon in primary astrocytes, human fetal astrocytes (HFA) were treated with gp120 IIIB and/or MA and the protein and mRNA expression levels of the CYPs were measured. Similar to SVGA astrocytes, gp120 and MA also 
a

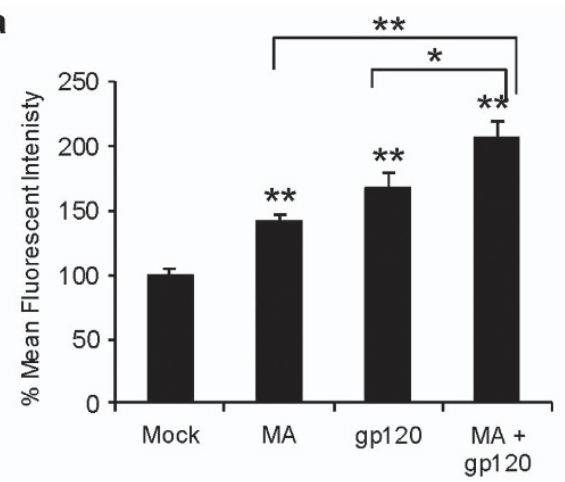

b

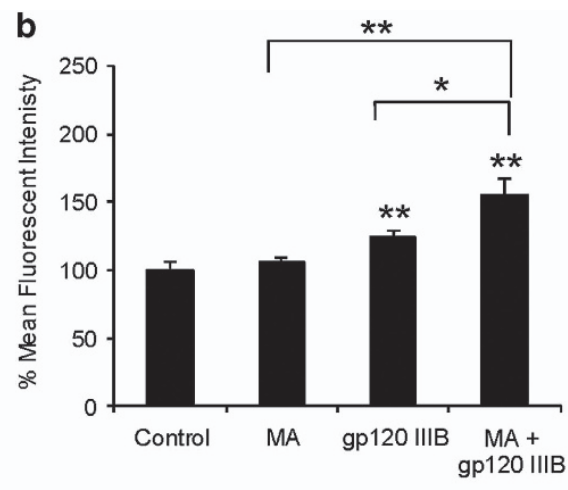

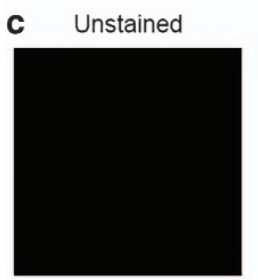

d Unstained

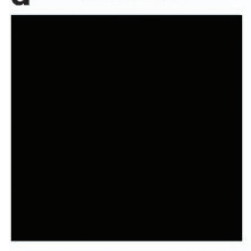

e Unstained

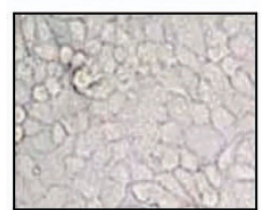

Mock

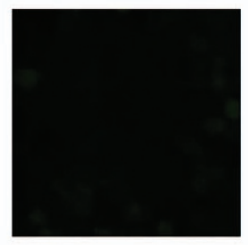

Control

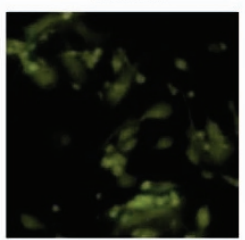

Mock

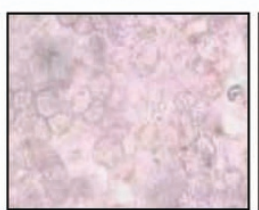

MA

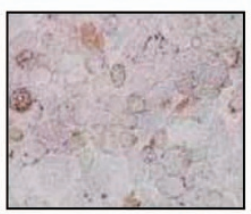

gp120

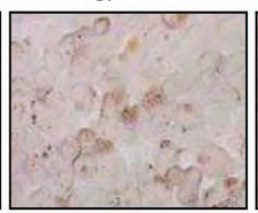

$\mathrm{MA}+\mathrm{gp} 120$

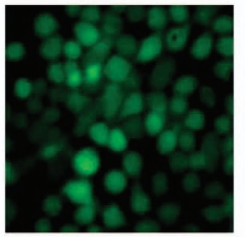

gp120

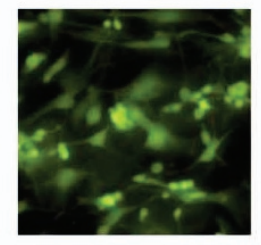

$M A+g p 120$

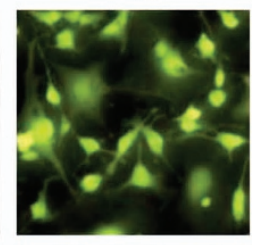

gp120 + MA

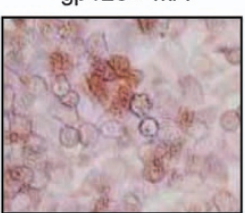

f

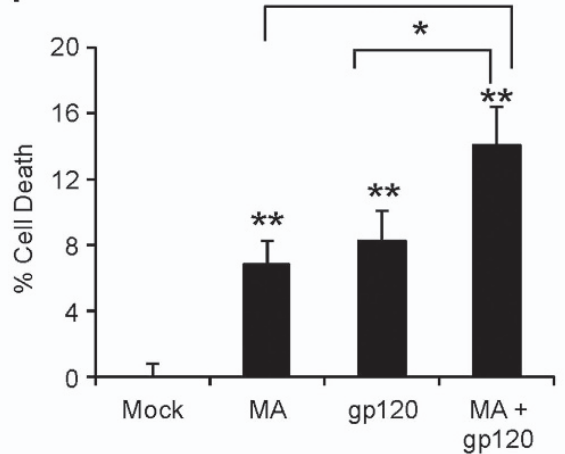

Figure 2 HIV-1 gp120 and MA additively increase oxidative stress in astrocytes. (a and c) SVGA astrocytes were seeded at $2.75 \times 10^{5}$ cells per well in 12 -well plates and treated with or without $500 \mu \mathrm{M}$ MA concomitantly with the transfection mix containing $2 \mu \mathrm{g}$ of gp120-plasmid for $24 \mathrm{~h}$. Mean fluorescence intensity was measured to quantify ROS production (a) and fluorescence was observed using the fluorescent microscope (c). (b and d) Primary human fetal astrocytes were seeded at $1 \times 10^{6}$ per well in 12 -well plates and treated with either $2 \mathrm{nM}$ gp $120 \mathrm{IIIB}$ or $500 \mu \mathrm{M}$ MA as well as both MA and gp120IIIB for $24 \mathrm{~h}$. The ROS production was quantified using the flow cytometer (b) and fluorescence was observed using the fluorescent microscope (d). SVGA astrocytes treated with MA and/or gp120 were stained for TUNEL (e) or treated with MTT (f) to measure cell death. For MTT assay, cell viability in mock-transfected cells was considered as the control and cell death was expressed as \% death in control. The bars represent mean \pm S.E. of at least three independent experiments with each treatment in triplicates. The $P$-value $\leq 0.05\left(^{*}\right)$ and $\leq 0.01\left(^{* *}\right)$ were considered statistically significant using Student's t-test and two-way analysis of variance (ANOVA) 

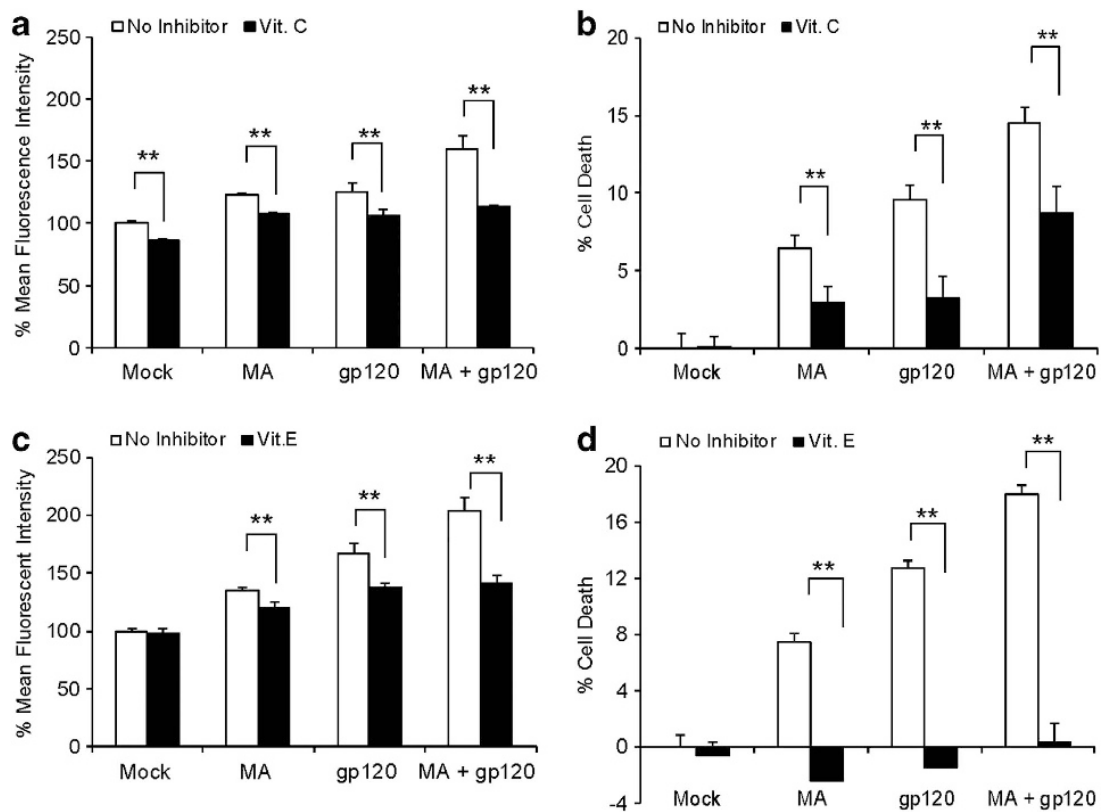

Figure 3 ROS quenchers reduced MA \pm gp120-induced oxidative stress and cell death. SVGA astrocytes were treated with or without vit. $\mathrm{C}$ and vit. E $1 \mathrm{~h}$ before the treatment with MA and/or gp120. ROS ( $\mathbf{a}$ and $\mathbf{c}$ ) was measured using the flow cytometer $24 \mathrm{~h}$ after the treatment and the effect on cell death (b and $\mathbf{d}$ ) was measured $48 \mathrm{~h}$ after the treatment. The bars represent mean \pm S.E. of at least three independent experiments with each treatment in triplicates. The $P$-value $\left.\leq 0.01{ }^{(*}\right)$ were considered significant using two-tailed Student's $t$-test and two-way analysis of variance (ANOVA)

showed additive increase in the levels of CYP2E1, CYP2B6, and CYP2D6 mRNA (Figure 4c) and protein (Figure 4d) in HFA primary cells. The analysis run for synergy using twoway ANOVA showed nonsignificant $P$-values, suggesting no synergistic interaction.

Role of CYP2E1 in gp120- and/or MA-mediated oxidative stress. To examine the role of CYP2E1 in oxidative stress, we pretreated astrocytes with different concentrations of diallylsulfide (DAS), a selective inhibitor of CYP2E1. Clearly, both 10 and $25 \mu \mathrm{M}$ DAS reduced the ROS generated by either MA and/or gp120 (Figure 4e). It is of note that DAS alone showed some decrease in the basal ROS production, but its efficacy against MA- and/or gp120-mediated oxidative stress was significant and dose-dependent $(P$ for trend $=0.01$ ). Although DAS did not significantly rescue the cell from death caused by MA alone, it significantly rescued the cell death $(P \leq 0.01)$ caused by gp120 alone and MA + gp120 (Figure 4f). In parallel experiments, DAS was also found to reduce the TUNEL staining in the cells treated with MA and/or gp120 (Figure 4g). Furthermore, we also specifically knocked down CYP2E1 using siRNA in order to confirm our findings with chemical inhibitor. As expected, the knockdown of CYP2E1 resulted into reduction of ROS (Figure $4 \mathrm{~h}$ ) and it also showed reduced TUNEL staining in the cells treated with MA and/or gp120 (Figure 4i). The specific knockdown of CYP2E1 was confirmed using western blotting, which showed $75-80 \%$ knockdown of CYP2E1 (Figure $4 \mathrm{~h}$ ). These results clearly suggest the involvement of CYP2E1 in oxidative stress and cell death induced by gp120, $\mathrm{MA}$, or both. We also tested fluoxetine and paroxetine, specific inhibitors for CYP2D6, and orphenadrine (OP), specific inhibitor for CYP2B6, on MA+gp120-mediated ROS generation. However, these antagonists failed to reduce the ROS formation, rather paroxetine and OP further increased oxidative stress (Supplementary Figure 2). In addition, we also specifically knocked down CYP2B6 and CYP2D6 using siRNA. However, as observed with chemical inhibitors, these siRNAs did not show any effect on ROS production (Supplementary Figure 3). Although, oxidative stress is one of the functional consequences of CYP enzyme activity, the possible role of CYP2D6 and CYP2B6 in other physiological functions cannot be disregarded.

NOX and metal chelation are involved in MA/gp120mediated oxidative stress and cell death. The NOX family of enzymes are responsible for the transfer of electrons across biological membranes and generation of ROS. ${ }^{31}$ In addition, various NOXs also serve as essential coenzymes coupled with CYP2E1-mediated electron transfer in the generation of ROS. ${ }^{32}$ To examine the involvement of NOX in gp120 \pm MA-mediated oxidative stress, we treated the SVGA astrocytes with various concentrations of diphenyleneiodonium (DPI), an inhibitor for NOX. DPI significantly reduced the ROS production observed with either MA or gp120 alone and MA+gp120 (Figure 5a) in a dosedependent manner $(P$ for trend $=0.01$ ). Furthermore, $25 \mathrm{nM}$ DPI rescued the cell death induced by MA and/or gp120 (Figure $5 b$ ), thereby confirming the role of NOX in MA/gp120mediated cell toxicity. Among the NOX family of enzymes, NOX2 and NOX4 isozymes are predominantly responsible for NOX-derived ROS in astrocytes. ${ }^{33,34}$ Therefore, we knocked down NOX2 and NOX4 using siRNA, which also abrogated the ROS produced by MA and gp120, either alone 
or in combination (MA \pm gp120) (Figures $5 c$ and d). Furthermore, control siRNA-transfected cells did not show any significant change in the ROS production, when compared with no-siRNA control for the respective treatment groups ( $P>0.3$ when measured using two-way ANOVA).

Superoxides $\left(\mathrm{O}_{2}^{--}\right)$generated via NOX are converted into $\mathrm{H}_{2} \mathrm{O}_{2}$, which is further converted into tertiary effector species such as hydroxyl radical $\left({ }^{\circ} \mathrm{OH}\right)$ via the Fenton-Weiss-Haber $(\mathrm{FWH})$ reaction. ${ }^{35,36}$ We therefore hypothesized that $\mathrm{FWH}$ reaction is a downstream mechanism of NOX-mediated ROS production. As increased expression of ferritin is an indicator of oxidative stress, ${ }^{37}$ we measured the expression of ferritin heavy chain in the cells treated with MA and/or gp120. We observed higher ferritin expressions in astrocytes treated with MA and/or gp120 than untreated controls (Figure 6a), which suggested the involvement of $\mathrm{Fe}^{+2} \leftrightarrow \mathrm{Fe}^{+3}$ cycle. Therefore, we treated astrocytes with various concentrations of deferoxamine (DFO), an inhibitor of $\mathrm{FWH}$ reaction, $1 \mathrm{~h}$ before the treatment with either MA or gp120 alone and MA + gp120. Among various doses used, $50 \mathrm{nM}$ DFO was found to reduce a
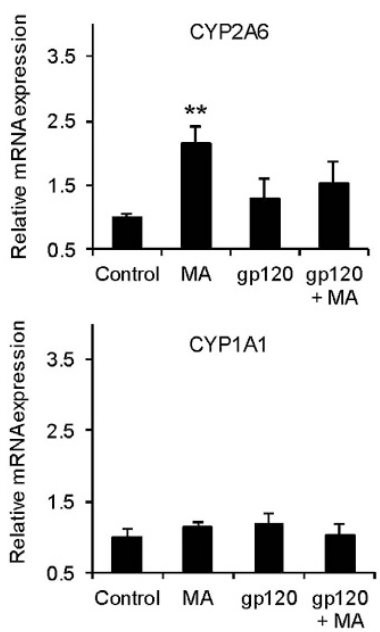

b
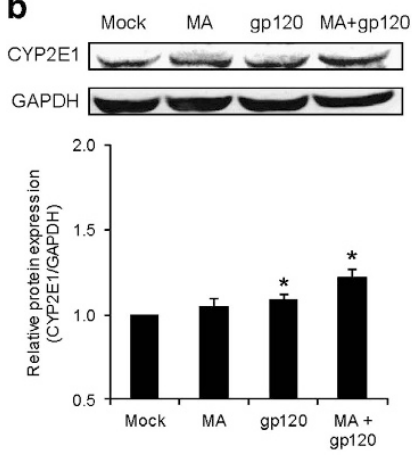

C

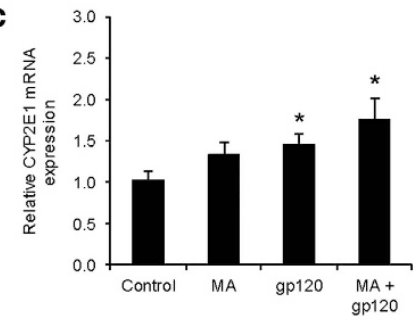

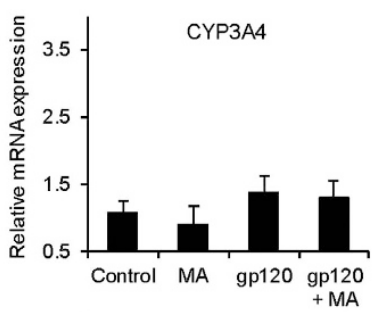

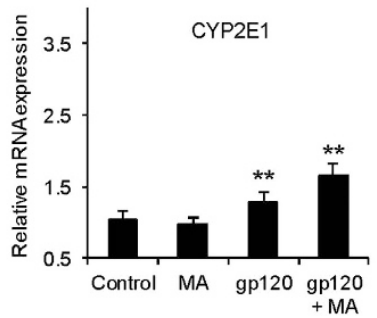

Mock MA gp120 MA+gp120
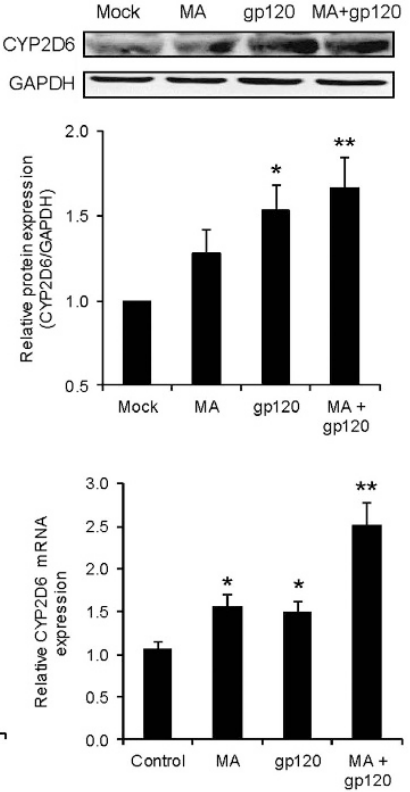
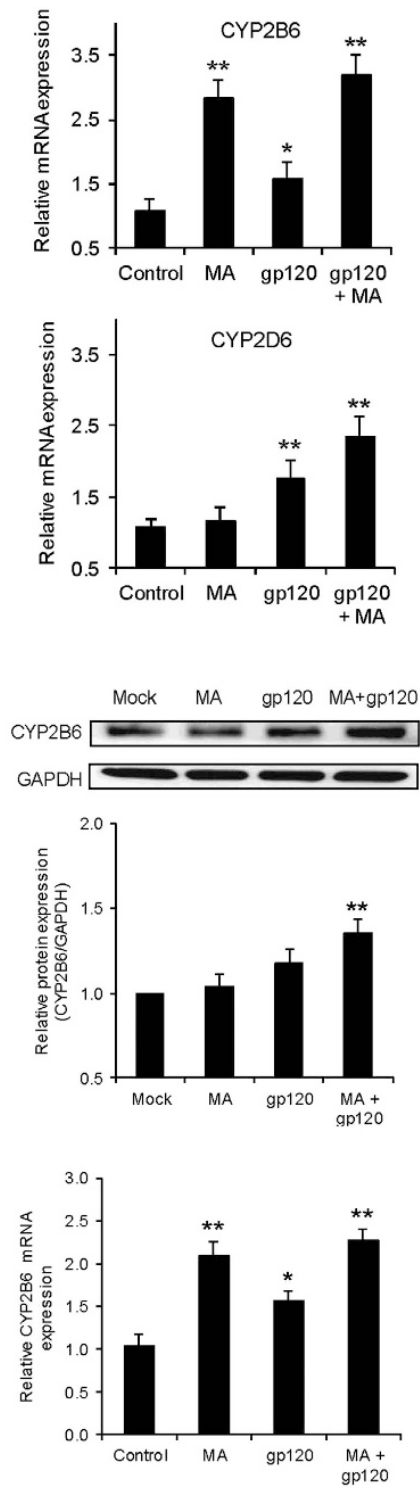

Figure 4 MA and gp120 induced the expression of various isozymes of CYP, and CYP2E1 played an important role in oxidative stress. (a and $\mathbf{b})$ SVGA astrocytes were treated with or without $500 \mu \mathrm{M}$ MA and transfected with gp120 for $6 \mathrm{~h}$ after transfection. Upon termination of the treatments, mRNA was isolated for its expressions for various isozymes of CYP and was measured (a) as described in Materials and Methods. Similarly, cells harvested $12 \mathrm{~h}$ post-treatment protein was isolated and the levels of CYPs were measured using western blotting (b), with GAPDH used as the housekeeping gene. (c and d) Primary human fetal astrocytes were treated with MA and/or gp120IIIB for 6 or $12 \mathrm{~h}$ and expressions of CYPs were measured at the levels of mRNA (c) and protein (d), respectively. (e-g) The effect of DAS, a selective CYP2E1 inhibitor, on ROS production (e), cell death (f), and TUNEL labeling $(\mathbf{g})$ in astrocytes treated with MA and/or gp120. (h-i) The effect of small interfering RNA (siRNA)-mediated knockdown of CYP2E1 on ROS (h) and TUNEL labeling (i) in MA- and/or gp120-treated SVGA astrocytes. The ROS production and cell death were compared with untreated control that was normalized at $100 \%$. Bar graphs show mean of at least three independent experiments. The blot is representative of three independent experiments. GAPDH was used to normalize the expressions of CYPs. The bars represent mean \pm S.E. of at least three independent experiments with each treatment in triplicates. The $P$-value $\leq 0.05\left({ }^{*}\right)$ and $\left.\leq 0.01{ }^{* *}\right)$ were considered statistically significant using two-tailed Student's t-test and two-way analysis of variance (ANOVA) 

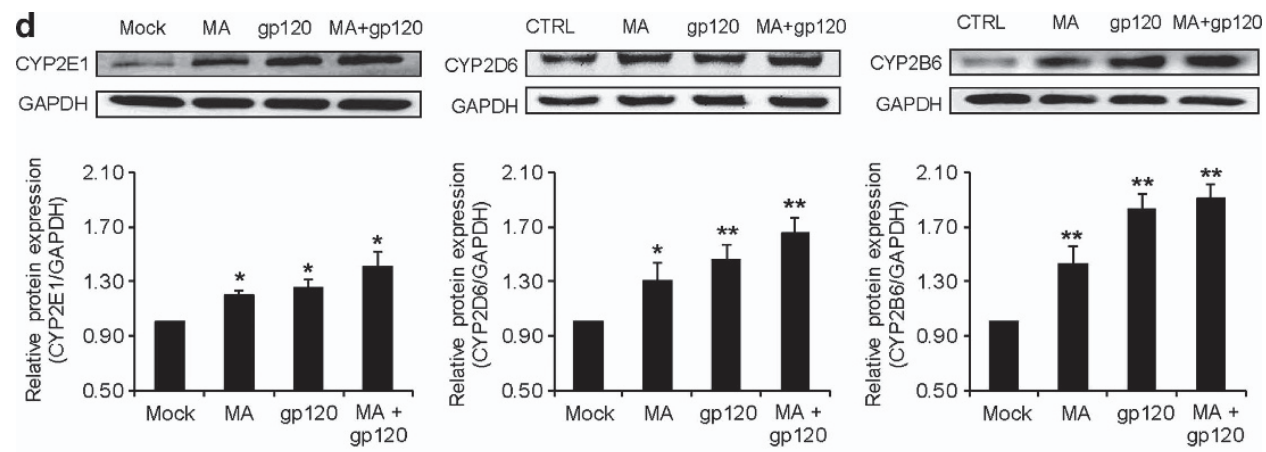

e
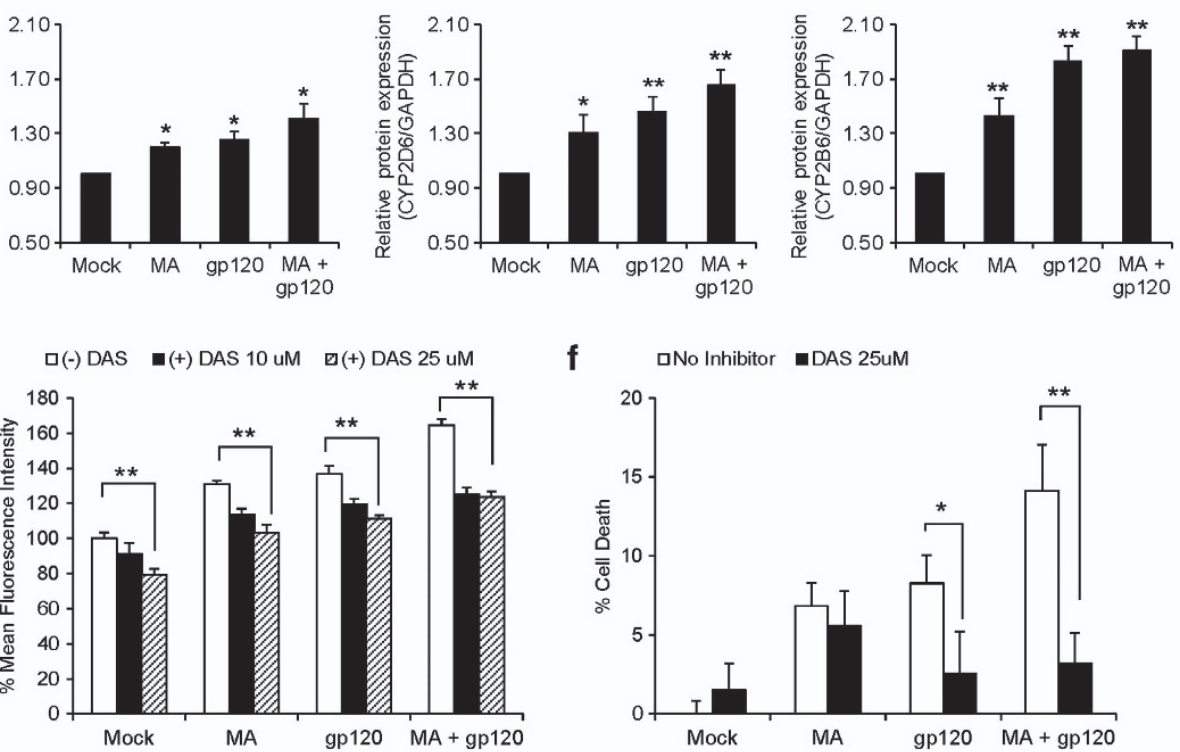

f

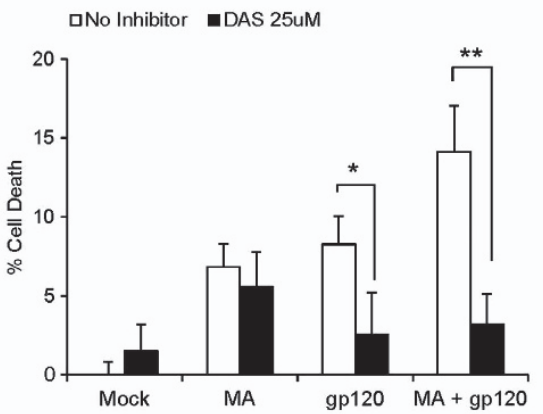

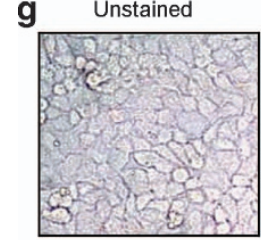

Positive Control

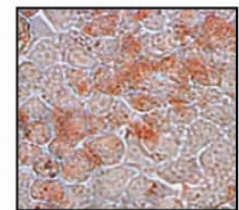

Mock

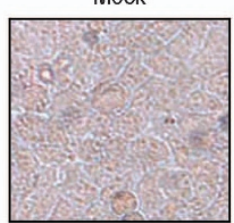

DAS

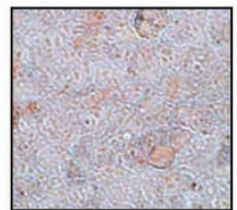

MA

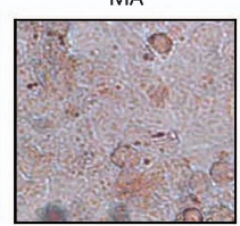

$D A S+M A$

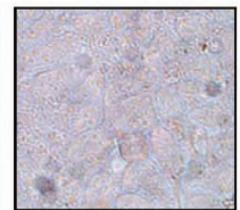

gp120

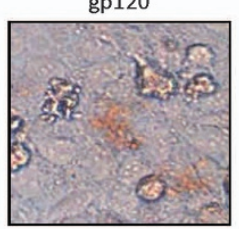

$\mathrm{DAS}+\mathrm{gp} 120$

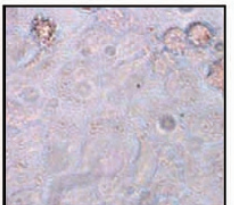

$\mathrm{MA}+\mathrm{gp} 120$

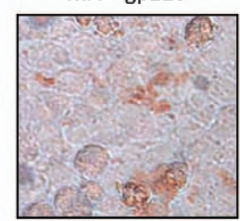

DAS + MA + gp 120

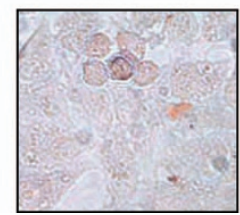

Figure 4 (Continued)

the ROS generated by gp120 alone as well as gp120+MA (Figure 6b). Furthermore, $50 \mathrm{nM}$ DFO also rescued the astrocytes from cell death induced by oxidative stress (Figure 6c). The involvement of iron cycle can also lead to increased protein carbonylation, which can further lead to apoptotic cell death. ${ }^{38,39}$ Therefore, we measured the levels of carbonylated protein in the astrocytes treated with MA and/or gp120. As expected, we observed increased levels of protein carbonylation (Figure 6d) upon treatments. Overall, these data suggested that NOX2 and NOX4 produced superoxides, which further underwent $\mathrm{FWH}$ chemistry to produce peroxides, leading to increased protein carbonylation. Taken together, these resulted in increased oxidative stress and consequently cell death.

Caspase-3 is involved in MA- and/or gp120-mediated apoptosis in astrocytes. Involvement of caspase- 3 is a classical mechanism of apoptosis in a variety of cells. We therefore examined the effect of MA and/or gp120 on caspase-3 protein expression and activity. Our results show increased protein expressions of caspase-3 when astrocytes were treated with MA and/or gp120. The immunoblots showed significantly increased expression of cleaved caspase-3 $(17 \mathrm{kDa})$ in the cells treated with MA, gp120, and $\mathrm{MA}+$ gp120. However, procaspase-3 isoform (35 kDa) was slightly reduced in the cells treated with gp120+MA (Figure 7a). Furthermore, astrocytes treated with either MA or gp120 alone showed increased caspase-3 cleavage activity as compared with untreated cells. In addition, cells treated with gp120 and MA showed significantly higher $(P \leq 0.01)$ caspase-3 cleavage activity as compared with either of the agents alone and the effect was found to be additive (Figure 7b). Furthermore, the inhibitors for ROS (Figure 7c), CYP2E1 (Figure 7d), NOX (Figure 7e), and FWH 

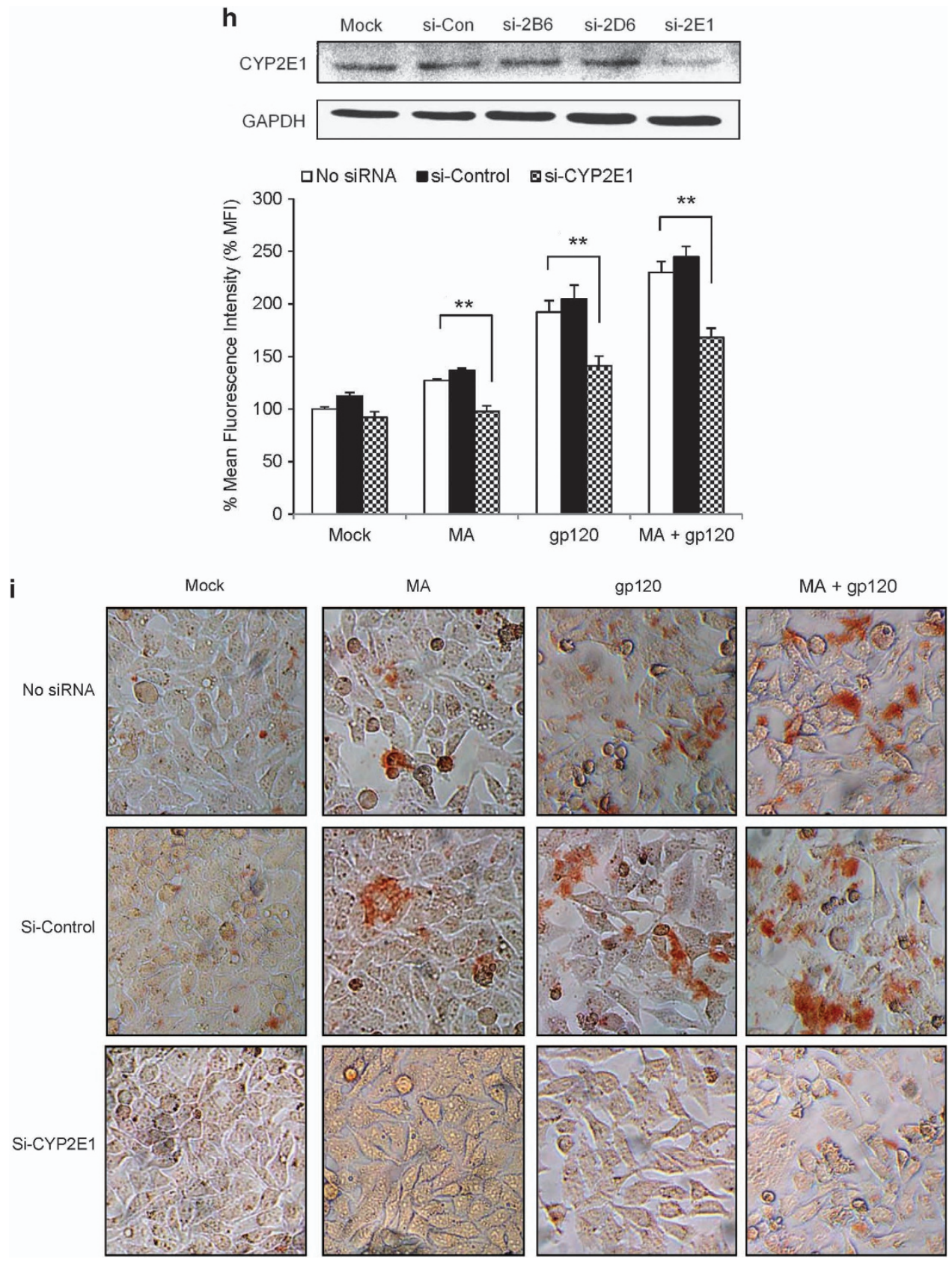

Figure 4 (Continued)

reaction (Figure 7f) significantly reduced MA/gp120mediated caspase-3 activity. These findings clearly suggested that pathways involving CYP2E1, NOX family of enzymes, and FWH reaction are responsible for MA- and/or gp120-mediated apoptosis in SVGA astrocytes.

\section{Discussion}

Substance abuse such as MA is thought to be an additional risk factor in worsening the HIV-associated neurodegeneration. ${ }^{9}$ Viral proteins, such as gp120, have been shown to interplay cooperatively with MA and damage BBB integrity in mouse brain. ${ }^{17}$ In addition, MA alone is also known to induce behavioral impairment in gp120 transgenic mice. ${ }^{40}$ However, there is no direct evidence that elucidates the mechanism responsible for the combined effect of MA- and gp120induced toxicities in the brain. We have recently shown that MA and gp120 can induce proinflammatory cytokine IL-6 via common signaling mechanism involving PI3K/Akt and NF- $k \mathrm{~B}$ pathways. ${ }^{6,41}$ On the other hand, an increasing body of literatures clearly suggests oxidative stress as one of the mediators of neurotoxicity induced by HIV-1 gp120 as well as MA independently. However, no attempt has been made to determine the fate of oxidative stress in a possible situation where HIV-infected individuals were MA user as well. This study was undertaken with the idea of determining whether 
a 口No Inhibitor aDPI $5 \mathrm{nM}$ GDPI $25 \mathrm{nM}$

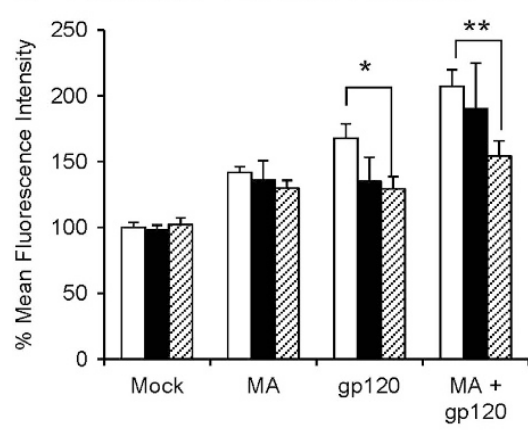

C

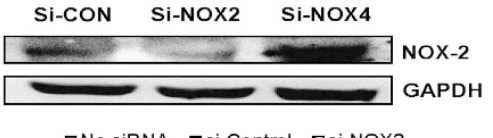

口No siRNA asi-Control asi-NOX2

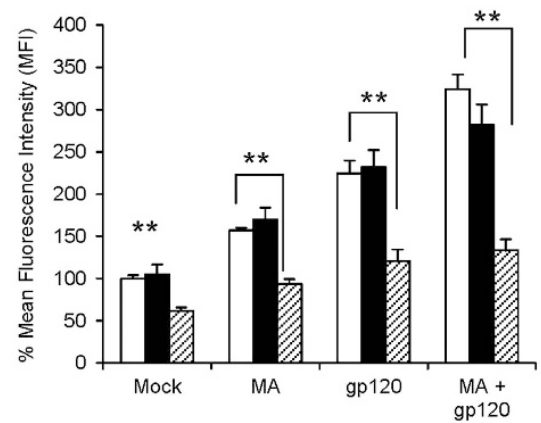

b 口No Inhibitor aDPI 25nM שDPI 50nM
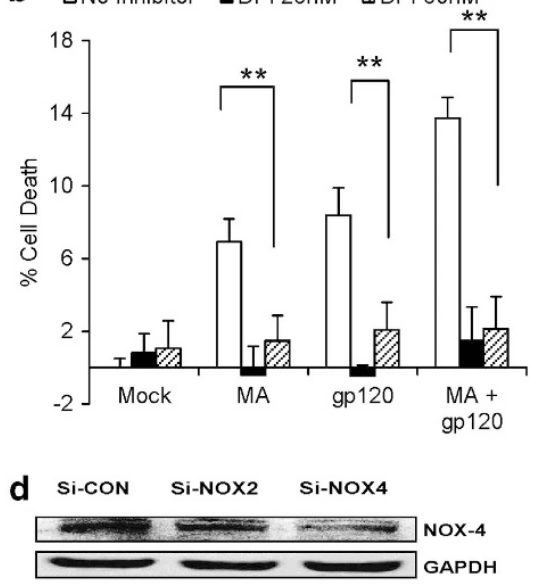

口No siRNA asi-Control שsi-NOX4

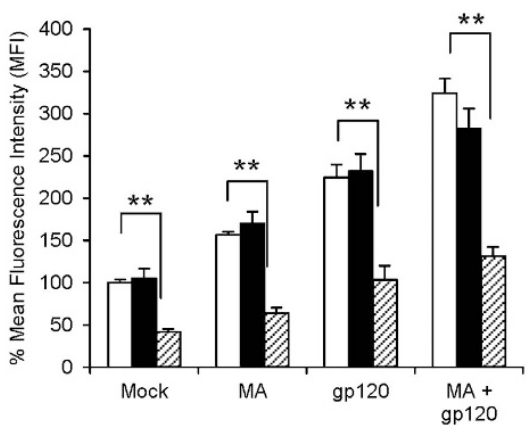

Figure 5 Role of NOX in MA- and/or gp120-induced oxidative stress and cell death. (a and $\mathbf{b}$ ) SVGA cells were treated with DPI, a selective inhibitor for NOX, at various concentrations $1 \mathrm{~h}$ before the treatment with MA and/or gp120 and the effect was observed on ROS production (a) and cell death (b). (c and d) Astrocytes were transfected with $10 \mathrm{nM}$ small interfering RNA (siRNA) targeting either NOX2 or NOX4 subunit of NOX family for $48 \mathrm{~h}$. These cells were further treated with MA and/or gp120. The effect of gene knockdown on ROS production was measured for NOX2 (c) and NOX4 (d). The gene knockdown was confirmed using western blotting for the efficiency of each siRNA. The cells transfected with $10 \mathrm{nM}$ of control siRNA was used as control, which showed no significant change in ROS production. The bars represent mean \pm S.E. of at least

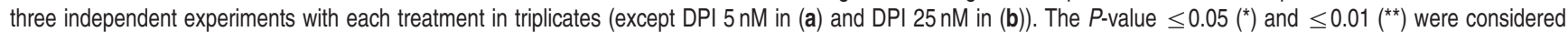
statistically significant using two-tailed Student's $t$-test and multiple analysis of variance (ANOVA)

gp120 and MA-mediated oxidative stress would cause increased apoptosis in astrocytes and whether CYP450 has any role in oxidative stress.

Oxidative stress is associated with cell toxicity in various neurodegenerative disorders such as Alzheimer's disease and Parkinson's disease. ${ }^{42}$ In addition, several reports have highlighted the role of oxidative stress in the pathology of HIVassociated neurocognitive disorders (HAND). ${ }^{43}$ This was further confirmed by our studies with morphine, wherein we showed morphine-mediated increased virus replication, ${ }^{44}$ accelerated disease progression, ${ }^{45}$ and increased oxidative stress $^{46,47}$ in macaque model of HIV/AIDS. The oxidative stress produced by either MA or gp120 has also been shown to have neurotoxic potential via various intermediates. MA, in particular, is found to increase oxidative stress predominantly via dopaminergic and glutamatergic mechanisms. ${ }^{10}$ The dopaminergic toxicity observed with MA is attributed to its structural similarity with dopamine. Furthermore, gp120 is shown to increase oxidative stress via glutathione and lipid peroxidation. ${ }^{8,48}$ Concurrent with the existing literatures, we also observed increased oxidative stress in astrocytes treated with gp120 and MA individually, in time- and concentrationdependent manners.

Recently, dopamine has been shown to regulate the expression of various CYP isozymes in the liver. ${ }^{49}$ Furthermore, Bromek et al. ${ }^{50}$ has shown that CYP2D increases dopamine formation in the brain. In addition to the metabolism of xenobiotics including substances of abuse, the role of CYPs in oxidative stress is unequivocally accepted in various tissues/organs including the brain. ${ }^{51}$ Specifically, the roles of CYP2E1 for alcohol metabolism-mediated toxicity and $\mathrm{CYP}_{2} \mathrm{A6}^{22}$ for tobacco/nicotine metabolism-mediated toxicity $^{52}$ have been implicated through the oxidative stress pathway in many tissues/organs. Our group along with others has previously reported that astrocytes also express many CYPs at variable levels, and they have demonstrated the role of CYPs in alcohol- and nicotine-mediated oxidative stress and toxicities. ${ }^{52,53}$ Similarly, MA has been shown to induce mRNA expression of CYP2E1 and activity of CYP2C6 in rats. ${ }^{54,55}$ Our observations with regard to increased expressions of CYP2A6, 2B6, and 2D6 by MA and CYP2E1, 2B6, and 2D 6 by gp120 are important to elucidate the roles of these 

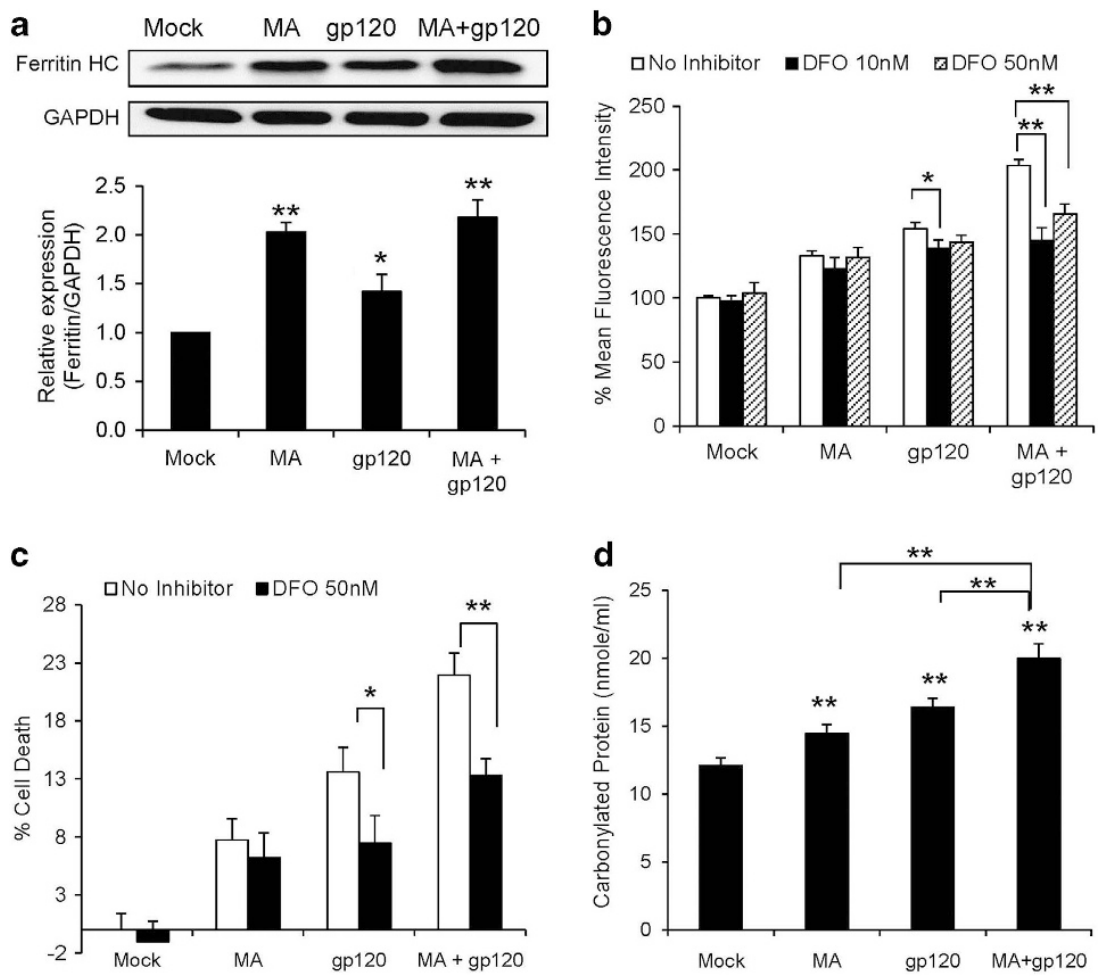

Figure 6 The expression of ferritin and the role of FWH chemistry in MA- and/or gp120-mediated oxidative stress and cell death. SVGA astrocytes were treated with MA and/or gp120 and the expressions of ferritin $\mathrm{HC}$ were measured using western blotting (a) and representative image is shown. Cells were treated with varying concentrations of DFO, an iron chelator used as FWH reaction antagonist, for $1 \mathrm{~h}$ before the treatment with MA and/or gp120 and the effect was observed on ROS (b) and cell death (c). (d) The amount of carbonylated proteins after $24 \mathrm{~h}$ as a result of treatment with MA and/or gp120. The ROS production and cell death were compared with untreated control that was normalized at $100 \%$. The bars represent mean \pm S.E. of at least three independent experiments with each treatment in triplicates. The $P$-value $\leq 0.05\left(^{*}\right)$ and $\leq 0.01\left(^{* *}\right)$ were considered statistically significant using two-tailed Student's $t$-test and multiple analysis of variance (ANOVA)

CYPs in oxidative stress, metabolism of certain xenobiotics, and homeostasis of other resident molecules such as dopamine in the brain. More importantly, the additive increase in the expressions of CYP2D6 and CYP2E1 by gp120 + MA is intriguing, which suggests a possibility that CYPs might have been involved in oxidative stress. This is the first evidence that shows an additive effect between MA or gp120 and CYP expression in the CNS.

Amphetamine analogs including MA are known to interact with CYP2D6 and alters its activity, ${ }^{56}$ which is further supported by the finding that selective inhibitors of CYP2D6 reduces the metabolism of ecstacy (MA analog) in vitro. ${ }^{57}$ However, the role of CYP2E1 in the metabolism of MA is largely unknown, except a few recent reports that have shown an involvement of CYP2E1 and CYP2B in the metabolism of either MA or pyrolysis product of MA ${ }^{58,59}$ CYP2E1 is mainly known for the metabolic activity in the presence of ethanol; however, its involvement in MA-mediated production of ROS leading to increased cell death is not known. We are able to confirm involvement of CYP2E1 in oxidative stress because DAS, a selective inhibitor for CYP2E1, significantly abrogated not only gp120/MA-mediated production of ROS but also cell death caused by these two stimulants individually or in combination. Unlike CYP2E1 inhibitor, the CYP2D6 and CYP2B6 inhibitors increased MA/gp120-induced ROS, suggesting lack of its role in MA/gp120-mediated oxidative stress. The increased oxidative stress by CYP2D6 inhibitors has been observed before and has been attributed to the direct effect of these inhibitors. ${ }^{60}$

The interaction of various CYPs with NADPH system is tightly regulated by NOX enzymes. ${ }^{61}$ CYP2E 1 is specifically involved in the metabolism of $\mathrm{R}-\mathrm{OH}$ compounds into aldehydes, which is coupled with the conversion of NADPH to $\mathrm{NADP}^{+}$and the released electron is consumed in the process. This NADP ${ }^{+}$is converted via non-CYP mechanism into NADPH, which is recycled back to NADPH by NOX family of enzymes (Figure 8). The NOX family of enzymes, particularly NOX2 and NOX4, is potentially known to increase ROS in astrocytes independently as well as in association with FWH chemistry. ${ }^{31,36}$ Furthermore, the superoxides and peroxides generated via NOX enzymes can result in increased expressions of ferritin and protein carbonylation ${ }^{38}$ as shown in this study as well. The role of NOX in substance abuse such as alcohol ${ }^{62}$ and $\mathrm{MA}^{18}$ is known in neuronal toxicity. Furthermore, the NOX enzymes have been implicated in therapeutic intervention of CNS disorders such as strokes and Alzheimer's disease. ${ }^{63,64}$ Our observations with NOX2 and NOX4 knockdown to rescue cells from oxidative damage support the possibility of using NOX as a target for developing potential therapeutics for the treatment of neuroAIDS, especially among MA users.

Various free radicals, generated during oxidative stress, may lead to multifactorial physiological effects in the cells via DNA damage, lipid peroxidation, or activation of apoptotic 
a

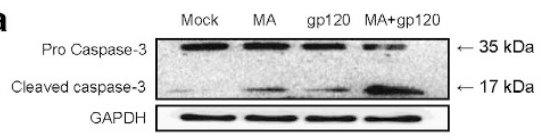

$\square$ Pro-caspase-3 active Caspase-3

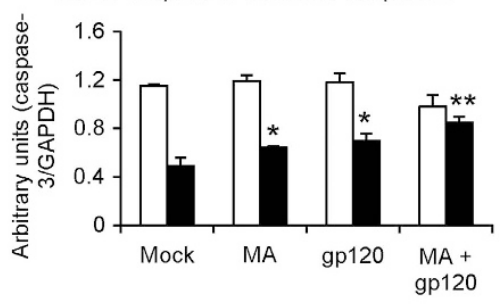

C

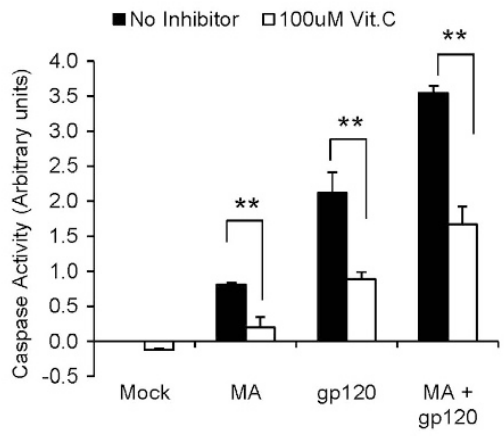

e

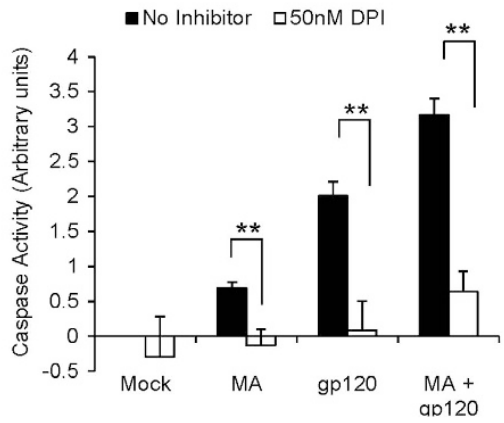

b

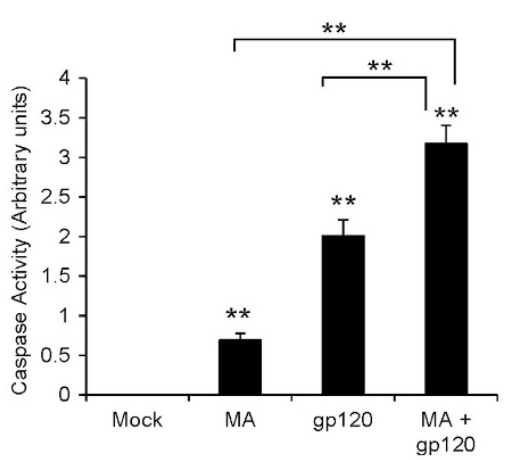

d No Inhibitor a25uM DAS
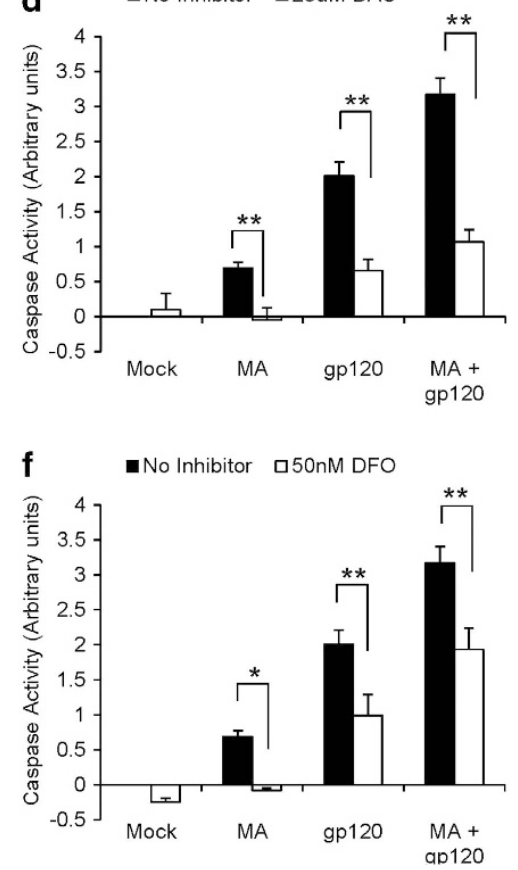

Figure 7 Caspase-3 activation is involved in the MA and/or gp120-mediated apoptosis in astrocytes. (a and $\mathbf{b})$ SVGA cells were treated with MA and/or gp120 for $24 \mathrm{~h}$ and the cytoplasmic proteins were obtained, which were used to measure procaspase-3 (35 kDa) and cleaved caspase-3 (17 kDa) protein expressions (a) and caspase-3 cleavage activity (b). The cells were also treated with either $100 \mu \mathrm{M}$ vit. C (c), $25 \mu \mathrm{M} \mathrm{DAS}$ (d), $50 \mathrm{nM}$ DPI (e), or $50 \mathrm{nM}$ DFO (f) $1 \mathrm{~h}$ before the treatment with MA and/or gp120 and the effect on caspase-3 cleavage activity was measured. The activity was normalized with basal levels in untreated control and reported as change in the activity. The bars represent mean \pm S.E. of three independent experiments with each treatment in triplicates. The $P$-value $\leq 0.05\left({ }^{*}\right)$ and $\leq 0.01\left(^{* *}\right)$ were considered statistically significant using two-tailed Student's $t$-test and multiple analysis of variance (ANOVA). The significant values shown above the bars were calculated using Student's $t$-test for comparison between the treatment and mock-transfected control

mechanisms. The ROS-mediated BBB damage has been shown to cause lipid peroxidation and loss of tight junction protein. ${ }^{13,17}$ MA and gp120 in combination are specifically shown to alter the levels of tight junction proteins to create a 'leaky' BBB, which may enhance the invasion of infected monocytes into the brain. ${ }^{17}$ Similarly, cocaine in association with gp120 has also been shown to increase ROS, which involves caspase- 3 and NF- $\kappa$ B activation to induce apoptosis in astrocytes. ${ }^{11}$ In our prior studies, we have shown an overlapping mechanism between MA and gp120 involving $\mathrm{NF}-\kappa \mathrm{B}$ activation. ${ }^{41}$ We have further shown the induction of proinflammatory cytokines as a result of NF- $\kappa$ B activation. In the present study, we observed an increase in the expression of cleaved caspase-3 protein in MA and/or gp120, which were further confirmed with the increase in the caspase- 3 cleavage activity. Our results are consistent with the recent finding that apoptosis is involved in gp120-mediated toxicity. ${ }^{23,65}$ Furthermore, caspase- 3 cleavage activity was inhibited by selective inhibitors for CYP2E1, NOX, and FWH reaction. Taken together, these findings suggest that the increase in caspase-3 expression and activity via ROS and cytokines via NF- $k \mathrm{~B}$ activation may lead to toxicity in astrocytes. Thus, there is a possibility of a cross-talk between these two mechanisms and therefore further studies are needed to investigate the effect of CYP-mediated ROS on cytokine production or vice versa. Our TUNEL staining was also consistent with this notion as both MA and gp120 independently as well as in combination led to increased DNA damage. Our observations with MTT assay 


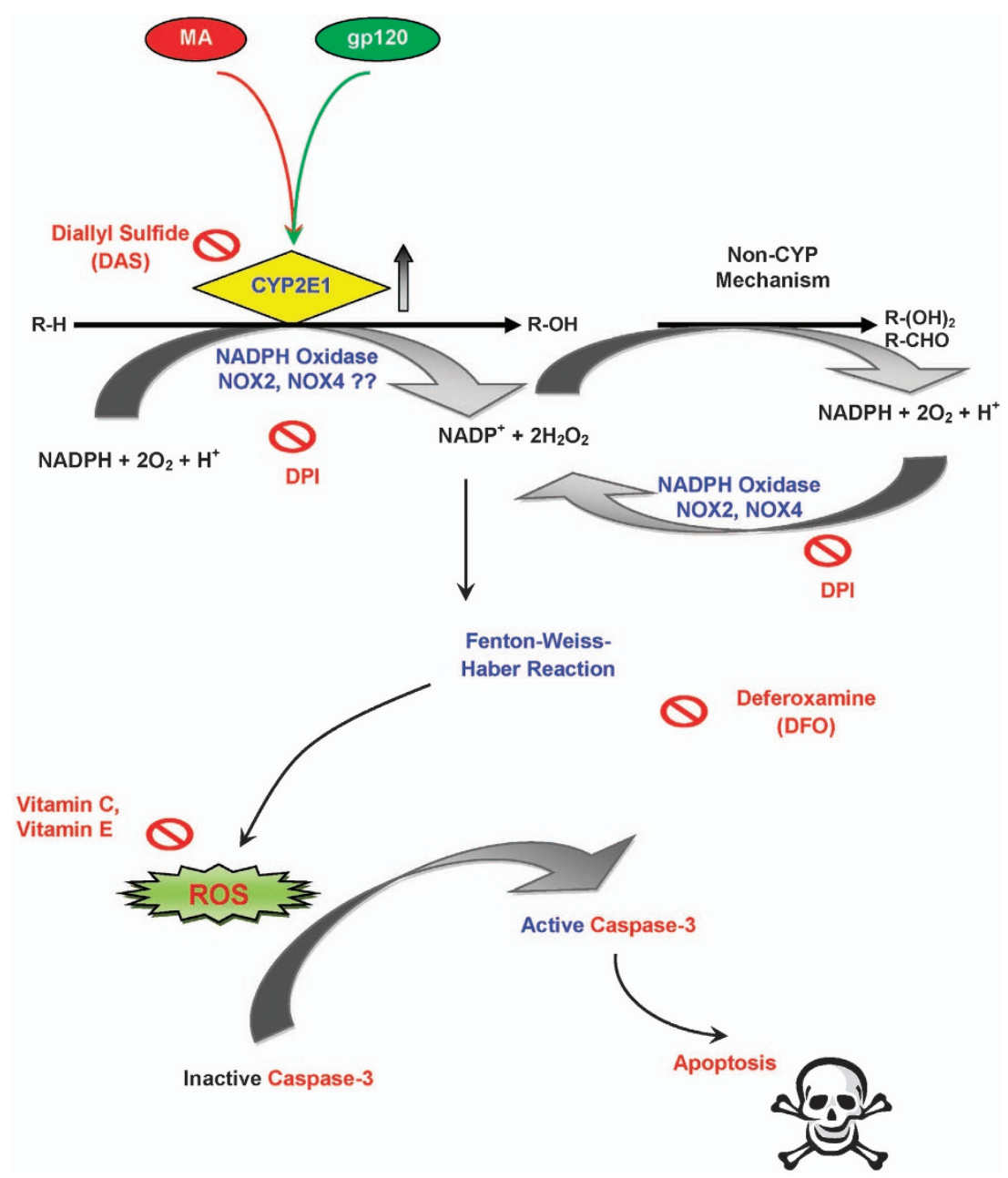

Figure 8 Schematic illustration of MA- and/or gp120-mediated oxidative stress. MA and/or gp120 increase the expressions of CYP2E1, which generates free electrons via conversion of NADPH to NADP ${ }^{+}$. The CYP2E1 reaction cycle produces ROS as a result of uncoupling of the reaction. In addition, the NADP ${ }^{+}$generated during this process is recycled via NOX to produce superoxides and peroxides. The superoxides can further generate peroxides through Fenton chemistry. The ROS generated via this mechanism increases the caspase-3 activity, which then induces DNA fragmentation, ultimately leading to apoptosis in astrocytes. The combination of MA and gp120 thus exacerbates the toxicity through common molecular mechanism(s). R-H represents MA or physiological substrates, such as dopamine. R-H may be oxidized to R-OH, which may further be oxidized to $\mathrm{R}-(\mathrm{OH})_{2}$ or $\mathrm{R}-\mathrm{CHO}$

further confirmed the toxic consequences of ROS production as a result of MA/gp120 interaction. In addition, inhibitors for CYP2E1, NOX, and FWH reaction abolished caspase-3 activity and apoptotic cell death, which clearly suggested that ROS, induced by gp120/MA interaction, was responsible for the apoptotic cell death.

In summary, results from our present study indicate that in the astrocytes, MA potentiates the gp120-mediated oxidative stress that may worsen the neurodegenerative complications in HIV-infected MA users. The involvement of CYP2E1 in interaction between gp120 and MA presents a novel opportunity to explore their further roles in neurotoxicity. Furthermore, it provides an opportunity to use this pathway as a target to find potentially novel pharmaceuticals. Specific inhibitors such as DAS, which is also a food additive, ${ }^{22}$ may potentially be used as food supplements/drugs in HIV-infected MA users to reduce neurotoxicity. The oxidative stressmediated increased toxicity by MA/gp120 in astrocytic cells also provides an opportunity to potentially use antioxidants in reducing MA-mediated HIV-1 pathogenesis in the patients who abuse MA. Finally, as peptide inhibitors against NOX have been shown to be protective in animal models, these inhibitors may potentially be used to reduce MA-induced HIV1 pathogenesis in the humans.

\section{Materials and Methods}

Cell culture and reagents. All the experiments were performed either in SVGA astrocytes, a clone of SVG astrocytes, or primary HFAs. HFAs were obtained from aborted fetuses and $>98 \%$ of the cells were found to be positive for GFAP (data not shown). Both the SVGA and the primary HFA cells were maintained at $37^{\circ} \mathrm{C}$ in a humidified chamber with $5 \% \mathrm{CO}_{2}$. The cells were cultured in Dulbecco's modified Eagle's medium supplemented with $10 \%$ fetal bovine serum, $1 \%$ L-glutamine, $1 \%$ sodium bicarbonate, $1 \%$ non-essential amino acids, and $0.1 \%$ gentamicin. All cells were cultured in 12-well plates and allowed to adhere overnight before any treatment was performed.

MA was purchased from Sigma-Aldrich (St. Louis, MO, USA). The plasmid expressing gp120 (pSyngp120 JR-FL) was originally constructed by Drs. Park and Seed (Department of Molecular Biology, and Melvin and Barbara Nessel Gene Therapy Center, Massachusetts General Hospital, Boston, MA, USA). Recombinant protein gp120IIIB and pSyngp120 JR-FL plasmids were obtained from the NIH 
AIDS Research and Reference Program (Germantown, MD, USA). DAS was obtained from Fisher Scientific (Pittsburgh, PA, USA). DPI, DFO, OP, TROLOX, vit. $\mathrm{E}$, fluoxetine, and paroxetine were purchased from Sigma-Aldrich. The treatments with antagonist were performed $1 \mathrm{~h}$ before the stimulus (MA and/or gp120) and maintained throughout the length of exposure. Specific antibodies against ferritin heavy chain (B12), CYP2E1 (H-21), and glyceraldehyde 3-phosphate dehydrogenase (GAPDH) (FL-335) were purchased from Santa Cruz Biotechnology (Santa Cruz, CA, USA), antibody against caspase- 3 , which detects procaspase 3 ( $35 \mathrm{kDa})$ and cleaved caspase-3 (17 kDa) was purchased from Cell Signaling Technology (Danvers, MA, USA) and antibody against CYP2D6 and CYP2B6 were purchased from Abcam (Cambridge, MA, USA). Specific siRNA for CYP2E1, CYP2B6, CYP2D6, NOX2, NOX4, and control siRNAs were purchased from Dhramacon (Thermo Fisher Scientific Inc., Waltham, MA, USA).

Transfection. SVGA astrocytes were transfected with $2 \mu \mathrm{g}$ plasmid encoding gp120 (pSyngp120 JR-FL) using Lipofectamine 2000 (Invitrogen Inc., Carlsbad, CA, USA) as discussed previously. ${ }^{5,6,14,41}$ Briefly, $3 \times 10^{5}$ SVGA cells per well were seeded in a 12-well plate and incubated overnight to allow them to adhere. The following day, the complete medium was removed and the cells were washed two times with PBS, followed by incubation with serum-free medium. The transfection reagents were added to the cells that were transfected and incubated for $5 \mathrm{~h}$. After $5 \mathrm{~h}$, the cells were washed two times with PBS and incubated with the complete medium for a total duration of $24 \mathrm{~h}$. Cells transfected with empty vector were used as controls in all the transfection experiments. For the treatments with inhibitor, SVGA astrocytes were pretreated with the antagonist $1 \mathrm{~h}$ before the transfection in serum-free medium and the antagonist was maintained throughout the duration of transfection.

In experiments involving siRNA transfections, SVGA cells were seeded at $8 \times 10^{5}$ cells per well in a six-well plate. The following day, cells were washed two times with PBS and transfected with 20 pmolof specific siRNA against NOX4, CYBB (NOX2), CYP2E1, CYP2B6, CYP2D6, or control siRNA for $48 \mathrm{~h}$. The cells were then recounted and $2.75 \times 10^{5}$ cells per well were seeded in a 12-well plate. These gene-depleted cells were then exposed to MA and/or gp120 for $24 \mathrm{~h}$ and ROS was measured. The efficiency of gene knockdown was confirmed using western blotting.

Real-time reverse transcriptase-polymerase chain reaction. To measure the mRNA expression levels of various CYPs, the cells were either treated with $500 \mu \mathrm{M}$ MA and/or transfected with plasmid encoding gp120. Upon termination of the treatment, total RNA was isolated using Qiagen RNeasy Mini Kit (Qiagen, Valencia, CA, USA). The RNA (120 ng) was reverse transcribed into cDNA at $37^{\circ} \mathrm{C}$ for 60 min using a 2-step TaqMan Gene Expression Kit (Applied Biosystems, Foster City, CA, USA). The cDNA obtained was amplified for GAPDH (4333764F), CYP1A1 (Hs01054794_m1), CYP2B6 (Hs03044636_m1), CYP2E1 (Hs00559367_m1), CYP3A4 (HS00430021_m1), CYP2D6 (Hs00164385_m1), and CYP2A6 (Hs0071162_m1) using the probe mix obtained from Applied Biosystems as per the manufacturer's protocol. The expression values for various CYPs were normalized using GAPDH as a housekeeping gene. Relative fold expressions for various genes were analyzed using the $2^{-\Delta \Delta C t}$ method.

Measurement of ROS production. To measure the oxidative stress produced in the astrocytes, the cells were treated with various agents for appropriate duration. After the termination of treatments, the cells were washed two times with PBS and incubated with $5 \mu \mathrm{M}$ 5-(and-6)-chloromethyl-2', $7^{\prime}$. dichlorodihydrofluorescein diacetate (CM- $\mathrm{H}_{2} \mathrm{DCFDA}$ ) (Molecular Probes, Carlsbad, CA, USA) for $30 \mathrm{~min}$ in serum-free medium at $37^{\circ} \mathrm{C}$. The cells were then washed two times with PBS to remove unloaded dye and the images were taken using Leica fluorescent microscope (DMI 3000B; Leica Microsystems Inc., Buffalo Grove, IL, USA). Unstained cells were used as experimental controls and the fluorescent images were obtained using excitation and emission wavelengths at 485 and $535 \mathrm{~nm}$, respectively.

To obtain the fluorescence intensity corresponding to ROS, the cells were collected and acquired using FITC wavelengths on FACSCanto II flow cytometer (BD Biosciences, San Jose, CA, USA). The ROS production was measured using unstained cells as negative controls and cells treated with $500 \mu \mathrm{M} \mathrm{H}_{2} \mathrm{O}_{2}$ as positive controls. The mean fluorescence intensities were compared between different treatments.

Western blotting. The protein levels were measured by analyses of western blots using whole-cell lysates obtained from astrocytes treated with appropriate reagents. Briefly, the cells were lysed using radioimmunoprecipitation assay
(RIPA) buffer (Boston BioProducts, Ashland, MA, USA) supplemented with Halt ${ }^{\mathrm{TM}}$ Protease Inhibitor Cocktail (Pierce Biotechnology, Rockford, IL, USA). The protein concentrations in the lysates were measured using BCA Protein Assay Kit (Pierce Biotechnology). The protein samples $(30 \mu \mathrm{g})$ were electrophoresed on a $10 \%$ polyacrylamide gel and transferred to PVDF membrane. Finally, the membrane was probed with appropriate primary and secondary antibodies for caspase-3, ferritin heavy chain (Ferritin HC), NOX2, NOX4, CYP2B6, CYP2E1, and CYP2D6 to measure their expression levels. The bands were detected using BM Chemiluminescence Western Blotting Substrate (POD) (Roche Applied Sciences, Indianapolis, IN, USA). The bands were analyzed using FlourChem HD2 software (Alpha Innotech, San Leandro, CA, USA) and the intensities were normalized using GAPDH as loading control.

Cell survival assay (MTT assay). The cell viability was measured using a colorimetric 3-(4,5-dimethylthiazol-2-yl)-2,5-diphenyltetrazolium bromide (MTT) assay. Briefly, $2 \times 10^{5}$ astrocyte cells were seeded in 12-well plates and treated with either the inhibitor or saline with subsequent treatment with MA and/or gp120 for $48 \mathrm{~h}$. Upon termination of the treatments, the medium was replaced with $0.2 \mathrm{mM}$ MTT containing medium and incubated at $37^{\circ} \mathrm{C}$ for $4 \mathrm{~h}$. The medium was carefully removed and purple formazan crystals were dissolved in $500 \mu \mathrm{l}$ DMSO containing $125 \mu$ l of Sorenson's glycine buffer. The color formation was measured using Benchmark Microplate Reader (Bio-Rad Laboratories, Hercules, CA, USA) with absorbance at $570 \mathrm{~nm}$ and reference at $650 \mathrm{~nm}$.

TUNEL assay. The measurement of cell viability was also correlated with DNA damage using TUNEL assay as per the manufacturer's protocol (GenScript, Piscataway, NJ, USA). Briefly, $2 \times 10^{5}$ cells per well were seeded in 12-well plates and the cells were exposed to the treatments with appropriate compounds. Upon treatments, the cells were air-dried for $5 \mathrm{~min}$ and fixed (4\% paraformaldehyde in PBS) for $30 \mathrm{~min}$ at room temperature. After fixation, they were incubated overnight at $4{ }^{\circ} \mathrm{C}$ and permeabilized using $1 \%$ Triton $\mathrm{X}-100$. The cells were then blocked in $3 \% \mathrm{H}_{2} \mathrm{O}_{2}$ in methanol and labeled with TUNEL reaction mixture (biotin-11-dUTP and TdT) and streptavidin-FITC. The smear of cells were washed with PBS to remove excess of labeling reagents and incubated with POD-conjugated anti-FITC substrate. Finally, 3,3'-diaminobenzidine (DAB) working reagent was added and the cells were observed under the light microscope. The images were taken using Leica DMI 300B (Leica Microsystems Inc., Buffalo Grove, IL, USA).

Caspase-3 activity assay. The caspase- 3 activity was measured using caspase-3 colorimetric assay kit (BioVision Inc., Milpitas, CA, USA) as per the manufacturer's protocol. Briefly, apoptosis was induced as per the treatments under investigation and the cells were lysed using lysis buffer. The protein concentration in the lysates was measured using BCA Protein Assay Kit (Pierce Biotechnology, Rockford, IL, USA) and $50 \mu$ of lysates containing $200 \mu \mathrm{g}$ protein was used for caspase- 3 activity. The lysates were mixed with $2 \times$ reaction buffer containing $10 \mu \mathrm{M}$ DTT and DEVD-pNA substrate and incubated at $37^{\circ} \mathrm{C}$ for $2 \mathrm{~h}$. Finally, the absorbance was measured using Benchmark Microplate Reader (Bio-Rad Laboratories) at $405 \mathrm{~nm}$ and the caspase activity was calculated with relative standard curve obtained using substrate alone.

Protein carbonylation assay. The measurement of carbonylated protein was performed using protein carbonyl colorimetric assay kit (Cayman Chemicals, San Francisco, CA, USA) as per the manufacturer's protocol. Briefly, the cells were treated and lysed with RIPA lysis buffer. The protein samples were checked for the absence of nucleic acid contamination and $200 \mu$ g proteins were used for the assay. The lysates were mixed with DNPH (2,4-dinitrophenylhydrazine) and incubated in the dark for $1 \mathrm{~h}$ followed by consecutive treatments with $20 \%$ and $10 \%$ trichloroacetic acid (TCA). This was followed by three washes with ethanol/ethyl acetate $(1: 1$ mixture and finally the pellet was resuspended in guanidine hydrochloride. The absorbance of the supernatants was measured at $370 \mathrm{~nm}$ using a microplate reader and carbonylated protein content was calculated.

Statistical analysis. The statistical analysis was performed to represent the data in mean \pm S.E. values. Results were based on at least three separate experiments unless specified with each experiment performed in triplicates. For the comparison between mock/control group, treatments were performed using two-tailed Student's $t$-test to calculate $P$-values, and $P$-value $\leq 0.05$ was considered statistically significant. The $P$-value $\leq 0.05$ was indicated by (*) and $\leq 0.01$ was indicated by '**' in the bar graphs. Experiments involving two variables 
were analyzed using two-way ANOVA to address whether they interact with each other in a synergistic manner. To examine dose-dependent effect of the inhibitors, results were analyzed using $P$-value for trend test using general linear model. No adjustments were made in the statistical analysis for multiple comparisons.

\section{Conflict of Interest}

The authors declare no conflict of interest.

Acknowledgements. We thank Dr. Peter Silverstein for critical reading of the manuscript. This work was supported by grants from National Institute on Drug Abuse (DA025528 and DA025011) and National Institute on Alcohol Abuse and Alcoholism (AA020806). The following reagent was obtained through the NIH AIDS Research and Reference Reagent Program, Division of AIDS, NIAID, NIH: pSyn gp120 JR-FL from Dr. Eun-Chung Park and Dr. Brian Seed.

1. Kaul M, Zheng J, Okamoto S, Gendelman HE, Lipton SA. HIV-1 infection and AIDS: consequences for the central nervous system. Cell Death Differ 2005; 12(Suppl 1): 878-892.

2. Carroll-Anzinger D, Kumar A, Adarichev V, Kashanchi F, Al-Harthi L. Human immunodeficiency virus-restricted replication in astrocytes and the ability of gamma interferon to modulate this restriction are regulated by a downstream effector of the Wnt signaling pathway. J Virol 2007; 81: 5864-5871.

3. Gonzalez-Scarano F, Martin-Garcia J. The neuropathogenesis of AIDS. Nat Rev Immunol 2005; 5: 69-81.

4. Shah A, Kumar A. HIV-1 gp120-mediated increases in IL-8 production in astrocytes are mediated through the NF-kappaB pathway and can be silenced by gp120-specific siRNA. J Neuroinflamm 2010; 7: 96.

5. Shah A, Singh DP, Buch S, Kumar A. HIV-1 envelope protein gp120 up regulates CCL5 production in astrocytes which can be circumvented by inhibitors of NF-kappaB pathway. Biochem Biophys Res Commun 2011; 414: 112-117.

6. Shah A, Verma AS, Patel KH, Noel R, Rivera-Amill V, Silverstein PS et al. HIV-1 gp120 induces expression of IL- 6 through a nuclear factor-kappa B-dependent mechanism: suppression by gp120 specific small interfering RNA. PLOS One 2011; 6: e21261.

7. Reddy PV, Gandhi N, Samikkannu T, Saiyed Z, Agudelo M, Yndart A et al. HIV-1 gp120 induces antioxidant response element-mediated expression in primary astrocytes: role in HIV associated neurocognitive disorder. Neurochem Int 2012; 61: 807-814.

8. Ronaldson PT, Bendayan R. HIV-1 viral envelope glycoprotein gp120 produces oxidative stress and regulates the functional expression of multidrug resistance protein-1 (Mrp1) in glial cells. J Neurochem 2008; 106: 1298-1313.

9. Silverstein PS, Shah A, Weemhoff J, Kumar S, Singh DP, Kumar A. HIV-1 gp120 and drugs of abuse: interactions in the central nervous system. Curr HIV Res 2012; 10: 369-383.

10. Silverstein PS, Shah A, Gupte R, Liu X, Piepho RW, Kumar S et al. Methamphetamine toxicity and its implications during HIV-1 infection. J Neurovirol 2011; 17: 401-415.

11. Yao H, Allen JE, Zhu X, Callen S, Buch S. Cocaine and human immunodeficiency virus type 1 gp120 mediate neurotoxicity through overlapping signaling pathways. J Neurovirol 2009; 15: 164-175.

12. Yamamoto BK, Raudensky J. The role of oxidative stress, metabolic compromise, and inflammation in neuronal injury produced by amphetamine-related drugs of abuse. J Neuroimm Pharmacol 2008; 3: 203-217.

13. Park M, Hennig B, Toborek M. Methamphetamine alters occludin expression via NADPH oxidase-induced oxidative insult and intact caveolae. J Cell Mol Med 2012; 16: 362-375.

14. Shah A, Silverstein PS, Singh DP, Kumar A. Involvement of metabotropic glutamate receptor 5 , AKT/PI3K signaling and NF-kappaB pathway in methamphetamine-mediated increase in IL-6 and IL-8 expression in astrocytes. J Neuroinflamm 2012; 9: 52.

15. Ramirez SH, Potula R, Fan S, Eidem T, Papugani A, Reichenbach $\mathrm{N}$ et al. Methamphetamine disrupts blood-brain barrier function by induction of oxidative stress in brain endothelial cells. J Cerebr Blood Flow Metab 2009; 29: 1933-1945.

16. LaVoie MJ, Hastings TG. Dopamine quinone formation and protein modification associated with the striatal neurotoxicity of methamphetamine: evidence against a role for extracellular dopamine. J Neurosci 1999; 19: 1484-1491.

17. Banerjee A, Zhang X, Manda KR, Banks WA, Ercal N. HIV proteins (gp120 and Tat) and methamphetamine in oxidative stress-induced damage in the brain: potential role of the thiol antioxidant $\mathrm{N}$-acetylcysteine amide. Free Radic Biol Med 2010; 48: 1388-1398.

18. Park MJ, Lee SK, Lim MA, Chung HS, Cho SI, Jang CG et al. Effect of alpha-tocopherol and deferoxamine on methamphetamine-induced neurotoxicity. Brain Res 2006; 1109: $176-182$.

19. Zhang X, Banerjee A, Banks WA, Ercal N. N-acetylcysteine amide protects against methamphetamine-induced oxidative stress and neurotoxicity in immortalized human brain endothelial cells. Brain Res 2009; 1275: 87-95.

20. Brown J 3rd, Theisler C, Silberman S, Magnuson D, Gottardi-Littell N, Lee JM et al. Differential expression of cholesterol hydroxylases in Alzheimer's disease. J Biol Chem 2004; 279: 34674-34681.
21. Elbaz A, Levecque C, Clavel J, Vidal JS, Richard F, Amouyel P et al. CYP2D6 polymorphism, pesticide exposure, and Parkinson's disease. Ann Neurol 2004; 55: 430-434.

22. Jin M, Ande A, Kumar A, Kumar S. Regulation of cytochrome P450 2e1 expression by ethanol: role of oxidative stress-mediated pkc/jnk/sp1 pathway. Cell Death Dis 2013; 4: e554.

23. Visalli V, Muscoli C, Sacco I, Sculco F, Palma E, Costa N et al. N-acetylcysteine prevents HIV gp 120-related damage of human cultured astrocytes: correlation with glutamine synthase dysfunction. BMC Neurosci 2007; 8: 106.

24. Shin EJ, Duong CX, Nguyen XK, Li Z, Bing G, Bach JH et al. Role of oxidative stress in methamphetamine-induced dopaminergic toxicity mediated by protein kinase Cdelta. Behav Brain Res 2012; 232: 98-113.

25. Beauvais G, Atwell K, Jayanthi S, Ladenheim B, Cadet JL. Involvement of dopamine receptors in binge methamphetamine-induced activation of endoplasmic reticulum and mitochondrial stress pathways. PLoS One 2011; 6: e28946.

26. Melega WP, Cho AK, Harvey D, Lacan G. Methamphetamine blood concentrations in human abusers: application to pharmacokinetic modeling. Synapse 2007; 61: 216-220.

27. Riviere GJ, Gentry WB, Owens SM. Disposition of methamphetamine and its metabolite amphetamine in brain and other tissues in rats after intravenous administration. J Pharmacol Exp Therap 2000; 292: 1042-1047.

28. Talloczy Z, Martinez J, Joset D, Ray Y, Gacser A, Toussi S et al. Methamphetamine inhibits antigen processing, presentation, and phagocytosis. PLoS Pathogen 2008; 4: e28.

29. Cohen GM, d'Arcy Doherty M. Free radical mediated cell toxicity by redox cycling chemicals. Br J Cancer Suppl 1987; 8: 46-52.

30. Klaunig JE, Kamendulis LM. The role of oxidative stress in carcinogenesis. Annu Rev Pharmacol Toxicol 2004; 44: 239-267.

31. Bedard K, Krause KH. The NOX family of ROS-generating NADPH oxidases: physiology and pathophysiology. Physiological reviews 2007; 87: 245-313.

32. Haorah J, Ramirez SH, Floreani N, Gorantla S, Morsey B, Persidsky Y. Mechanism of alcohol-induced oxidative stress and neuronal injury. Free Radic Biol Med 2008; 45: 1542-1550.

33. Abramov AY, Jacobson J, Wientjes F, Hothersall J, Canevari L, Duchen MR. Expression and modulation of an NADPH oxidase in mammalian astrocytes. J Neurosci 2005; 25: 9176-9184.

34. Pawate $S$, Shen $Q$, Fan $F$, Bhat NR. Redox regulation of glial inflammatory response to lipopolysaccharide and interferongamma. J Neurosci Res 2004; 77: 540-551.

35. Fridovich I. Superoxide dismutases. An adaptation to a paramagnetic gas. J Biol Chem 1989; 264: 7761-7764

36. van Golen RF, van Gulik TM, Heger M. Mechanistic overview of reactive species-induced degradation of the endothelial glycocalyx during hepatic ischemia/reperfusion injury. Free Radic Biol Med 2012; 52: 1382-1402.

37. Friedman A, Arosio P, Finazzi D, Koziorowski D, Galazka-Friedman J. Ferritin as an important player in neurodegeneration. Parkinson Relat Disord 2011; 17: 423-430.

38. Cattaruzza M, Hecker M. Protein carbonylation and decarboylation: a new twist to the complex response of vascular cells to oxidative stress. Circ Res 2008; 102: 273-274.

39. Suzuki YJ, Carini M, Butterfield DA. Protein carbonylation. Antioxid Redox Signal 2010; 12: 323-325.

40. Henry BL, Geyer MA, Buell M, Perry W, Young JW, Minassian A et al. Behavioral effects of chronic methamphetamine treatment in HIV-1 gp120 transgenic mice. Behav Brain Res 2013; 236: 210-220

41. Shah A, Silverstein PS, Kumar S, Singh DP, Kumar A. Synergistic cooperation between methamphetamine and HIV-1 gsp120 through the P13K/Akt pathway induces IL- 6 but not IL-8 expression in astrocytes. PLoS One 2012; 7: e52060.

42. Dasuri K, Zhang L, Keller JN. Oxidative stress, neurodegeneration, and the balance of protein degradation and protein synthesis. Free Radic Biol Med 2012; 62: 170-185.

43. Mollace V, Nottet HS, Clayette P, Turco MC, Muscoli C, Salvemini D et al. Oxidative stress and neuroAIDS: triggers, modulators and novel antioxidants. Trends Neurosci 2001; 24: 411-416.

44. Kumar R, Torres C, Yamamura Y, Rodriguez I, Martinez M, Staprans S et al. Modulation by morphine of viral set point in rhesus macaques infected with simian immunodeficiency virus and simian-human immunodeficiency virus. $J$ Virol 2004; 78: 11425-11428.

45. Kumar R, Orsoni S, Norman L, Verma AS, Tirado G, Giavedoni LD et al. Chronic morphine exposure causes pronounced virus replication in cerebral compartment and accelerated onset of AIDS in SIV/SHIV-infected Indian rhesus macaques. Virology 2006; 354: 192-206.

46. Perez-Casanova A, Husain K, Noel RJ Jr, Rivera-Amill V, Kumar A. Interaction of SIV/SHIV infection and morphine on plasma oxidant/antioxidant balance in macaque. Mol Cell Biochem 2008; 308: 169-175.

47. Perez-Casanova A, Noel RJ Jr, Rivera-Amill V, Husain K, Kumar A. Morphine-mediated deterioration of oxidative stress leads to rapid disease progression in SIV/SHIV-infected macaques. AIDS Res Hum Retrovirus 2007; 23: 1004-1007.

48. Louboutin JP, Strayer DS. Blood-brain barrier abnormalities caused by HIV-1 gp120: mechanistic and therapeutic implications. Scientific World J 2012; 2012: 482575.

49. Wojcikowski J, Daniel WA. The brain dopaminergic system as an important center regulating liver cytochrome P450 in the rat. Expert Opin Drug Metab Toxicol 2009; 5: 631-645.

50. Bromek E, Haduch A, Golembiowska K, Daniel WA. Cytochrome $P 450$ mediates dopamine formation in the brain in vivo. J Neurochem 2011; 118: 806-815. 
51. Hedlund E, Gustafsson JA, Warner M. Cytochrome P450 in the brain; a review. Curr Drug Metab 2001; 2: 245-263.

52. Ande A, Earla R, Jin M, Silverstein PS, Mitra AK, Kumar A et al. An LC-MS/MS method for concurrent determination of nicotine metabolites and the role of CYP2A6 in nicotine metabolite-mediated oxidative stress in SVGA astrocytes. Drug Alcohol Depend 2012; 125 49-59.

53. Meyer RP, Gehlhaus M, Knoth R, Volk B. Expression and function of cytochrome $p 450$ in brain drug metabolism. Curr Drug Metab 2007; 8: 297-306.

54. Takimoto $\mathrm{T}$, Ujike $\mathrm{H}$, Nakamura $\mathrm{K}$, Iwahashi $\mathrm{K}$. [Increase expression of CYP2E1 mRNA after methamphetamine administration in rats]. Nihon Arukoru Yakubutsu Igakkai zasshi = Japanese journal of alcohol studies \& drug dependence 2002; 37: 163-167.

55. Dostalek M, Jurica J, Pistovcakova J, Hanesova M, Tomandl J, Linhart I et al. Effect of methamphetamine on cytochrome P450 activity. Xenobiotica 2007; 37: 1355-1366.

56. Wu D, Otton SV, Inaba T, Kalow W, Sellers EM. Interactions of amphetamine analogs with human liver CYP2D6. Biochem Pharmacol 1997; 53: 1605-1612.

57. Ramamoorthy Y, Yu AM, Suh N, Haining RL, Tyndale RF, Sellers EM. Reduced (+ / - )3,4-methylenedioxymethamphetamine ('Ecstasy') metabolism with cytochrome P450 2D6 inhibitors and pharmacogenetic variants in vitro. Biochem Pharmacol 2002; 63: 2111-2119.

58. Sanga M, Younis IR, Tirumalai PS, Bland TM, Banaszewska M, Konat GW et al. Epoxidation of the methamphetamine pyrolysis product, trans-phenylpropene, to trans-phenylpropylene oxide by CYP enzymes and stereoselective glutathione adduct formation. Toxicol Appl Pharmacol 2006; 211: 148-156.

59. Valoti M, Fusi F, Frosini M, Pessina F, Tipton KF, Sgaragli GP. Cytochrome P450dependent $\mathrm{N}$-dealkylation of L-deprenyl in C57BL mouse liver microsomes: effects of in vivo pretreatment with ethanol, phenobarbital, beta-naphthoflavone and L-deprenyl. Eur J Pharmacol 2000; 391: 199-206.

60. Lee CS, Kim YJ, Jang ER, Kim W, Myung SC. Fluoxetine induces apoptosis in ovarian carcinoma cell line OVCAR-3 through reactive oxygen species-dependent activation of nuclear factor-kappaB. Basic Clin Pharmacol Toxicol 2010; 106: 446-453.

61. Eid AA, Gorin Y, Fagg BM, Maalouf R, Barnes JL, Block K et al. Mechanisms of podocyte injury in diabetes: role of cytochrome P450 and NADPH oxidases. Diabetes 2009; 58 : $1201-1211$.

62. Wang X, Ke Z, Chen G, Xu M, Bower KA, Frank JA et al. Cdc42-dependent activation of NADPH oxidase is involved in ethanol-induced neuronal oxidative stress. PLoS One 2012; 7: e38075.

63. Sorce S, Krause KH, Jaquet V. Targeting NOX enzymes in the central nervous system: therapeutic opportunities. Cell Mol Life Sci 2012; 69: 2387-2407.

64. Cairns B, Kim JY, Tang XN, Yenari MA. NOX inhibitors as a therapeutic strategy for stroke and neurodegenerative disease. Curr Drug Targets 2012; 13: 199-206.

65. Hu S, Sheng WS, Lokensgard JR, Peterson PK, Rock RB. Preferential sensitivity of human dopaminergic neurons to gp120-induced oxidative damage. J Neurovirol 2009; 15: 401-410.

(c) (-) Cell Death and Disease is an open-access journal published by Nature Publishing Group. This work is licensed under a Creative Commons Attribution-NonCommercialShareAlike 3.0 Unported License. To view a copy of this license, visit http://creativecommons.org/licenses/by-nc-sa/3.0/

\section{Supplementary Information accompanies this paper on Cell Death and Disease website (http://www.nature.com/cddis)}

